\title{
Observed Changes in Extreme Temperature over the Global Land Based on a Newly Developed Station Daily Dataset
}

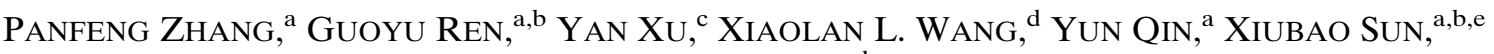 \\ AND YUYU REN ${ }^{\mathrm{b}}$ \\ ${ }^{a}$ Department of Atmospheric Science, School of Environmental Studies, China University of Geosciences, Wuhan, China \\ ${ }^{\mathrm{b}}$ Laboratory for Climate Studies, National Climate Center, China Meteorological Administration, Beijing, China \\ ${ }^{\mathrm{c}}$ National Meteorological Information Center, China Meteorological Administration, Beijing, China \\ ${ }^{\mathrm{d}}$ Climate Research Division, Atmospheric Science and Technology Directorate, Science and Technology Branch, \\ Environment Canada, Toronto, Ontario, Canada \\ ${ }^{\mathrm{e}}$ South China Sea Institute of Oceanology, Chinese Academy of Sciences, Guangzhou, China
}

(Manuscript received 30 October 2018, in final form 31 August 2019)

\begin{abstract}
This paper presents an analysis of changes in global land extreme temperature indices (1951-2015) based on the new global land surface daily air temperature dataset recently developed by the China Meteorological Administration (CMA). The linear trends of the gridpoint time series and global land mean time series were calculated by using a Mann-Kendall method that accounts for the lag- 1 autocorrelation in the time series of annual extreme temperature indices. The results, which are generally consistent with previous studies, showed that the global land average annual and seasonal mean extreme temperature indices series all experienced significant long-term changes associated with warming, with cold threshold indices (frost days, icing days, cold nights, and cold days) decreasing, warm threshold indices (summer days, tropical nights, and warm days) increasing, and all absolute indices (TXx, TXn, TNx, and TNn) also increasing, over the last 65 years. The extreme temperature indices series based on daily minimum temperatures generally had a stronger and more significant trend than those based on daily maximum temperatures. The strongest warming occurred after the mid-1970s, and a few extreme temperature indices showed no significant trend over the period from 1951 to the mid-1970s. Most parts of the global land experienced significant warming trends over the period 1951-2015 as a whole, and the largest trends appeared in mid- to high latitudes of the Eurasian continent.
\end{abstract}

\section{Introduction}

Global mean surface temperature has increased over the last 100 years (Cubasch et al. 2013; Jones et al. 2012; Sun et al. 2017b). A changing climate may lead to changes in the frequency, intensity, duration, and timing of weather and climate extremes and can probably result in unprecedented weather-related disasters. If exposure and vulnerability remain unchanged, extreme weather and climatic events will have direct negative impact on natural and human systems (Handmer et al. 2012; Seneviratne et al. 2012). During the period of 19802010, the global annual economic losses caused by extreme weather and climatic events have ranged from a few billion U.S. dollars to more than $\$ 200$ billion (in 2010 dollars), with the highest value in 2005 (Handmer

Corresponding author: G. Y. Ren, guoyoo@cma.gov.cn et al. 2012). A better understanding of long-term change of extreme climate thus cannot only contribute to climate change detection, attribution and projection, but can also improve management of extreme-climaterelated disaster risk.

During the last two decades, great progress was made in the studies of both global and regional longterm changes in extremes, thanks to the efforts of the joint Expert Team on Climate Change Detection and Indices (ETCCDI) of the WMO Commission for Climatology (CCL) and World Climate Research Programme (WCRP) Climate Variability and Predictability (CLIVAR) project, which organized a series of regional workshops to develop, calculate and analyze a suite of extreme climate indices (Frich et al. 2002; Peterson et al. 2002; Easterling et al. 2003; Aguilar et al. 2005; Vincent et al. 2005, 2011; Peterson 2005; Zhang et al. 2005a; Klein Tank et al. 2006; New et al. 2006; 
TABLE 1. Summary of data sources used in GLSDT-V1.0. Shown in the table are the priority grade (1 for first priority and 4 for least priority) of each dataset when included in GLSTD-V1.0, the number of total stations contained in each of the datasets, and the number of unique stations that each data source provides for GLSTD-V1.0.

\begin{tabular}{lclrr}
\hline \hline Source & Priority & \multicolumn{1}{c}{ Name/country } & No. of total stations & No. of unique stations \\
\hline Global & 2 & GHCND (Menne et al. 2012a,b) & 30519 & 24127 \\
& 3 & GSOD $^{\mathrm{a}}$ & 28514 & 9630 \\
Regional & 4 & CPC $^{\text {b }}$ & 11267 & 3390 \\
Country & 1 & ECA\&D (Klein Tank et al. 2002) & 2872 & 2811 \\
& 1 & Mainland of China (Cao et al. 2016) & 2419 & 2419 \\
& 1 & Russia & 223 & 88 \\
& 1 & Australia (Trewin 2001) & 703 & 72 \\
& 1 & South Korea & 22 & 22 \\
\hline
\end{tabular}

${ }^{\mathrm{a}} \mathrm{ftp} / / / \mathrm{ftp} \cdot$ ncdc.noaa.gov/pub/data/gsod.

${ }^{\mathrm{b}}$ https://www.cpc.ncep.noaa.gov/.

Alexander et al. 2006; Peterson and Manton 2008; Donat et al. 2013a). A total of 27 core indices (including 16 extreme temperature indices) and the corresponding calculation procedures (e.g., RClimDex and FClimDex) were formulated (X. Zhang et al. 2011), which were also widely used for studies of regional extreme temperature change (Yan et al. 2002; Klein Tank and Können 2003; Zhai and Pan 2003; Vincent and Mekis 2006; Brown et al. 2010; Zhou and Ren 2011; Xu et al. 2013; Sharma and Babel 2014; Fonseca et al. 2016; Sun et al. 2017a; Jayawardena et al. 2018).

Extreme climate datasets, for example, the Met Office Hadley Centre climate extremes datasets HadEX (Alexander et al. 2006) and HadEX2 (Donat et al. 2013a), and the Global Historical Climatology Network-Daily datasets HadGHCND (Caesar et al. 2006; Donat et al. 2013b) and GHCNDEX (Donat et al. 2013b), were developed to facilitate the analyses of global extreme climate change. Most of the daily temperature datasets were sourced from the European Climate Assessment dataset, the Global Historical Climatology Network-Daily dataset, and a series of regional workshops on extreme climate and covered a period from 1951 to recent years. Generally, the results of the analyses based on these datasets showed widespread and significant changes in the temperature extremes associated with climate warming, with those indices derived from daily minimum temperature exhibiting larger and more significant trends over the past decades (Alexander et al. 2006; Caesar et al. 2006; Donat et al. 2013a,b).

A new global land surface daily temperature dataset was recently developed by National Meteorological Information Center of the China Meteorological Administration (CMA), under the framework of the national research project of public welfare supported by the Ministry of Science and Technology of China (Ren et al.
2014; Xu et al. 2014). This work was based on the CMA Global Land Surface Daily Temperature (GLSDT-V1.0) dataset, which was an integrated international and national dataset with a good observational coverage in some regions especially in East Asia, permitting a new analysis of the global change of the main extreme temperature indices over the period 1951-2015.

The rest of this paper is organized as follows: the data and methods are first described in section 2. In particular, the data quality control, the homogeneity test procedures, extreme temperature indices and their calculation, and the methods of gridding, area weight averaging, trend estimate, and significance test are introduced in this section. The results are then presented in section 3. The discussion and conclusions are offered in sections 4 and 5, respectively.

\section{Data and methods}

\section{a. Data sources and data integration}

This study was based on the GLSDT-V1.0 (Ren et al. 2014; Xu et al. 2014) and China Homogenized Historical Temperature Dataset (CHHTD-V1.0) developed by the National Meteorological Information Center, CMA (Cao et al. 2016).

GLSDT-V1.0 is an integrated daily temperature dataset that is from three global sources [Global Historical Climatology Network-Daily (GHCND), Global Surface Summary of the Day (GSOD), and Climate Prediction Center (CPC)], one regional source [European Climate Assessment and Dataset (ECA\&D)], and five national sources (mainland of China, Russia, Australia, South Korea, and Vietnam). All the data in the GLSDT-V1.0 global sources and regional sources are open access, and the data in national sources are collected through bilateral exchanges with relevant countries (Table 1). 
The integration of multiple data sources mainly includes the following steps:

1) Data standardization. The datasets come from different sources, with station naming rules, data units, precisions, missing values codes, observational time system, and data formats being different. Therefore, it is necessary to standardize the data from various sources first. The processing steps are as follows:

(i) Unified station identification code. Referring to the station naming rules of GHCND (Menne et al. 2012a,b) data products, the first 2 digits are national codes, the middle digit is the data source identifier (if it is a WMO station number, the logo is "W"), and the last 8 digits retain the original station code of each source. If the station code is less than 8 digits, " 0 " was added to front as prefix.

(ii) Unified data units. Fahrenheit degrees were converted to Celsius degrees $\left({ }^{\circ} \mathrm{C}\right)$.

(iii) Unified data precision. The precision of the original daily temperature data is generally $0.1^{\circ} \mathrm{C}$, but the temperature data of the United States are mostly stored in whole Fahrenheit degrees, which is equivalent to a precision of $0.56^{\circ} \mathrm{C}$; most of the Canada data have a precision of $0.5^{\circ} \mathrm{C}$, and many of the Mexican records have a precision of $1^{\circ} \mathrm{C}$ (Zhang et al. 2009; Peterson et al. 2008). The precision is lower than the standard of $0.1^{\circ} \mathrm{C}$ recommended by World Meteorological Organization (WMO 2008), which would affect the estimation of the trends and means of the four relative threshold indices (TN10p, TN90p, TX10p, TX90p) because the quantile estimator may be related to data resolution (Zhang et al. 2009; Peterson et al. 2008). Therefore, we added a small uniform random number from the interval $(-0.5,0.5)$ to each daily temperature series $\left(T_{\max }\right.$ and $\left.T_{\min }\right)$ and then rounded it to the nearest $0.1^{\circ} \mathrm{C}$ when computing the four relative threshold indices, following the proposal by Zhang et al. (2009). Other indices analyzed in this study were calculated by using the original daily temperature series that had not been processed by adding any random numbers because the calculation of these indices does not need to estimate the quantile.

(iv) Shifting Chinese data backward by 1 day. The data of China's ground-based manual meteorological stations are observed at 2000-2000 Beijing time (BT) before around year 2003. In line with global data, the time system of China's stations was converted to 0000-0000 BT. For example, the daily maximum and minimum temperature from 2000 BT 2 January to 2000 BT 3 January is taken as the daily maximum and minimum temperature of 3 January because the daily maximum temperature always appears around 1300-1600 BT, and the daily minimum temperature always appears around 0600-0900 BT. This practice can be problematic in some special cases (about 1\%). For example, suppose that the temperature began to drop sharply after 2000 BT 3 January, which caused the daily minimum temperature on 3 January to probably appear between 2000 and 2400 BT instead of around $0600-0900$ BT. Currently, there is no better way to solve this problem.

(v) Unified data formats. In each station's data file, from left to right are the station number, date, climate element (maximum and minimum temperature), and quality control code, respectively.

(vi) Unified missing values code. The missing values code of a climate element (maximum temperature and minimum temperature), longitude and latitude, and elevation are marked as -999.9 .

2) Checking and integration of the repetitive stations. The data from different sources may contain duplicated stations. The stations will be regarded as duplicated ones on the condition that the WMO station codes are the same, or the latitude and longitude are exactly the same (the precision of latitude and longitude used in this study is $0.01^{\circ}$ ), or the latitude and longitude are close (difference of longitude and/or latitude between the stations of two data sources is less than $0.50^{\circ}$ ) and at least $60 \%$ records of the two source series during the study period are identical.

It is necessary to make further analysis for the duplicated stations to decide which stations should be retained. The stations with the longer series were retained. If the series length is same, then the stations series with the higher priority were retained. The priority of data was assigned based on the data sources, the frequency of updates, and the length of time series (see Table 1). The integrity and quality of data product released by the national meteorological agencies of China, South Korea, Australia, Russia, and Vietnam are relatively high, so these data products have the highest priority.

The dataset of CHHTD-V1.0 (Cao et al. 2016) had undergone a rigorous quality control and had been homogenized through the software RHtestsV3 (Wang and Feng 2010). The dataset has the best coverage of homogeneous daily temperature data in the mainland of China. Therefore, in order to make the best use of the existing homogeneous dataset, we replaced the part of 
the dataset for the mainland of China in the GLSDT-V1.0 with the CHHTD-V1.0.

We also used the dataset of stratospheric aerosol optical depth at $550 \mathrm{~nm}$ (Sato et al. 1993) that is available online (https://data.giss.nasa.gov/modelforce/strataer/). This dataset starts in 1850 and ends in July 2012. Considering the time period in this study, we only use the data between January 1951 and December 2011.

\section{b. Data quality control}

The dataset GLSDT-V1.0 had undergone a quality control when it was developed in 2014. After the two datasets of GLSDT v1.0 and CHHTD-V1.0 (Cao et al. 2016) were integrated to one, we conducted a new quality control that was mainly based on the module embedded in the software RClimDex (Zhang and Feng 2004). This work was performed following the 6-step checks below:

1) Whether the latitude and longitude values of the stations are out of bounds. The longitude and latitude values of each station should be limited between $-180^{\circ}$ and $180^{\circ},-90^{\circ}$ and $90^{\circ}$, respectively.

2) Whether the records are repetitive. The data of different months for the same station were checked for repetition. For example, the daily maximum temperature records for the whole years of 1959 and 1979 are the same at station AG000060590, and these two years data were replaced by missing values.

3) Whether the dates are repetitive. The results show that there are not any repetitive dates.

4) The climatological limit value of the temperature. Because the highest temperature and the lowest temperature reported for the globe in literature (Cerveny et al. 2007) were $57.8^{\circ}$ and $-89.4^{\circ} \mathrm{C}$, respectively, the daily temperature values that fall outside of this range (from $-89.4^{\circ}$ to $57.8^{\circ} \mathrm{C}$ ) were regarded as missing values.

5) The internal consistency. Daily minimum and maximum temperatures were set to missing values if the daily minimum temperature is larger than the daily maximum temperature.

6) The climate extreme value. The maximum range of daily minimum (or maximum) temperature was defined as five standard deviations (std) of the reference period (1961-90) mean value, that is, [mean $\pm 5 \times$ std]. Daily temperatures that were found falling outside of this range were replaced by missing values. It is possible that an extremely small portion of these outliers could be a true climatic extreme that was excluded, and this treatment may have made the extreme temperature indices change of certain stations or grid boxes less extreme.

Finally, stations that have no more than 15 days of missing values in a year and no more than 15 years of missing values during the reference period 1961-90 were retained. Totally, there are 12295 such stations, which were selected for use in the following analysis.

\section{c. Data homogeneity}

Homogenization is a more complicated problem when compared with the problems of data quality. The inhomogeneity of data series can be caused by the changes of nonclimatic factors (e.g., observing procedures and practice, station relocation, and observing times), which will make the estimate of trend of climate change unreliable. There is not always a coherent approach to cope with the problem of inhomogeneity (Peterson et al. 1998). A number of global or regional homogeneous monthly datasets had been developed (Menne and Williams 2009; Lawrimore et al. 2011; Jones et al. 2012; Vincent et al. 2012; Xu et al. 2018). However, only a few homogenized regional daily temperature datasets have been developed (Vincent et al. 2002; Wijngaard et al. 2003; Brunet et al. 2006; Li and Yan 2009; Trewin 2013; $\mathrm{Xu}$ et al. 2013; Cao et al. 2016) because of the difficulty caused by the largely spatiotemporal variability of daily temperature (Vincent et al. 2012) and the sensitivity of daily temperature to topography and local environment (Trewin and Trevitt 1996).

In this study, although the datasets of the mainland of China and Australia had been homogenized (Cao et al. 2016; Trewin 2001), the data in other regions have not been adjusted for homogeneity. To avoid erroneous trend estimates caused by the nonclimatic factors as much as possible, however, we used the penalized maximal $F$ test method of RHtestsV4 software (Wang 2008a,b; Wang and Feng 2013) to test the homogeneity of all the station data series without a reference series. If step changes of data series were detected, they would be excluded. Because of the lack of metadata, and also since some of these step changes detected may sometimes reflect true climatic shifts, a high confidence threshold of $99.99 \%$ was adopted, which means that only the most substantial inhomogeneities would be detected and excluded. This would be a reasonable approach that was also applied for other large datasets such as ECA\&D (Klein Tank et al. 2002) and HadEX (Alexander et al. 2006). In total, 1074 out of the 12295 stations were identified as inhomogeneous at the high confidence level and were thus excluded from our subsequent analysis. Given that the daily maximum/minimum temperature of GSOD dataset may be calculated from incomplete days and most of the GSOD stations located in the areas where the daily temperature records are already well covered by other datasets, we finally excluded most of GSOD stations, except for the 64 stations in Africa and South America where the station 
(a) Temperature stations (10372)

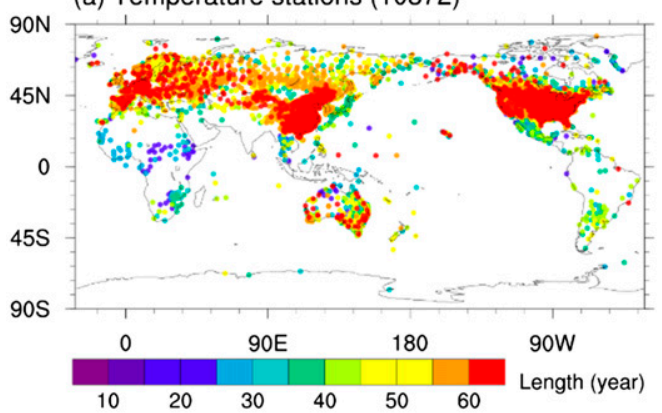

(c) The number of stations in the grid

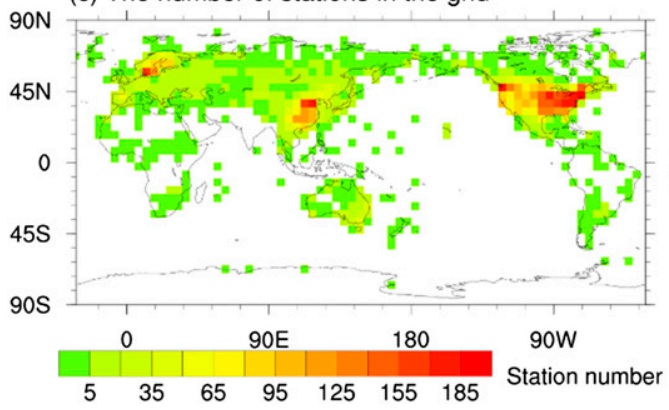

(b) The number of stations each year

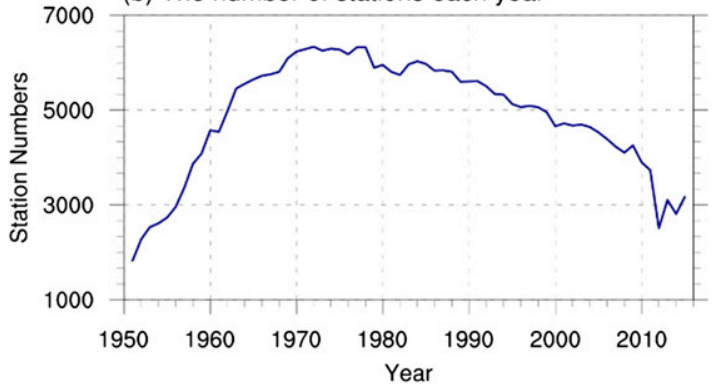

(d) The ratio of non-gaussian distribution

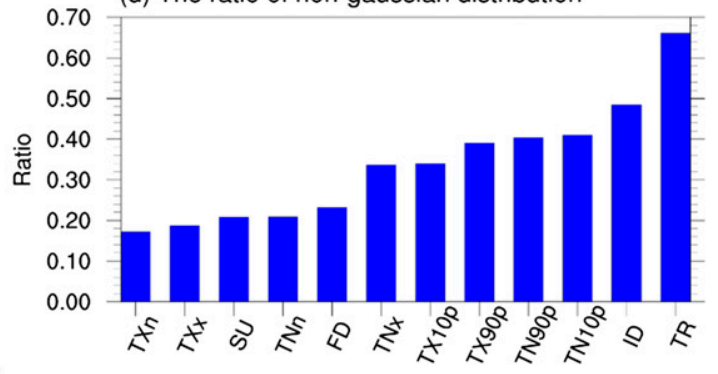

FIG. 1. (a) Locations of temperature stations used in this study. The colors represent the length of time series of stations. The number in parentheses indicates the total number of stations. (b) The number of stations each year. (c) The number of stations in the grid. (d) The station ratio of non-Gaussian distribution for each of the 12 extreme temperature indices.

coverage was sparse. Therefore, the new dataset of GLSDT-V1.0 thus contains in total 10372 stations for use in this study. The stations are shown in Fig. 1a, the yearly counts of stations with data in Fig. $1 b$, and the number of stations in each grid point with at least one station in Fig. 1c.

Figures 1a and 1c show the uneven distribution of the stations across the continents. The densest observations are seen in three regions: Europe, East Asia, and the United States. Blank areas and sparser observations are visible in Africa, West Asia, South Asia, Southeast Asia, and South America. The yearly count of stations is characterized by a low value in the early 1950s, a high level of over 6000 stations during 1961-95, and a decline after the mid-1990s (Fig. 1b). The recent decline in data coverage mainly occurs in Europe, Asia, Africa, and Canada (Figs. 2a-d). Compared with other datasets including HadEX2 (Donat et al. 2013a) and GHCNDEX (Donat et al. 2013b), more available temperature stations were added in this research, especially in East Asia. The temperature stations included only in this research but not in GHCNDEX and HadEX2 are shown in Figs. $2 \mathrm{f}$ and $2 \mathrm{~h}$. The largest increase in number of stations in GLSDT can be seen in Asia, but other continents also witness increase in varied extents in the data coverage. It should be noted that the HadEX2 dataset only incorporated the United States and Australia subsets of the stations with homogeneous data series, and this is the main reason why GLSDT has more stations in these regions compared to HadEX2. Overall, this research applies more stations in East Asia, Europe, and South America compared to the GHCNDEX; and in East Asia, the United States, and continents of the Southern Hemisphere compared to HadEX2.

\section{d. Extreme temperature indices}

To make comparisons with previous studies, 12 extreme temperature indices recommended by ETCCDI were used. Four indices [the warm spell duration index (WSDI), cold spell duration index (CSDI), growing season length (GSL), and daily temperature range (DTR)] included in the recommendation of ETCCDI were also calculated but not analyzed in this paper. The 27 ETCCDI indices are defined by the intensity, frequency, and duration of abnormal temperature events. (Detailed definitions and calculation of these indices are described at http://etccdi.pacificclimate.org/list_27_indices.shtml.)

We developed a new procedure, based on the functions of $\mathrm{R}$ language package climdex.pcic (Bronaugh 2015), to batch calculate the extreme indices for multistations, which was different from the climdex.pcic package that can only be used to calculate a single station 
(a) Stations in year 1955

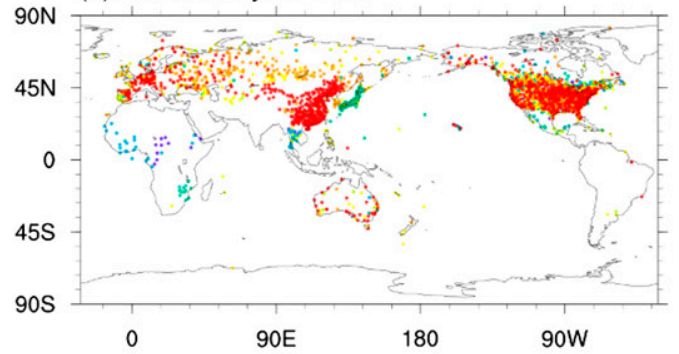

(c) Stations in year 2000

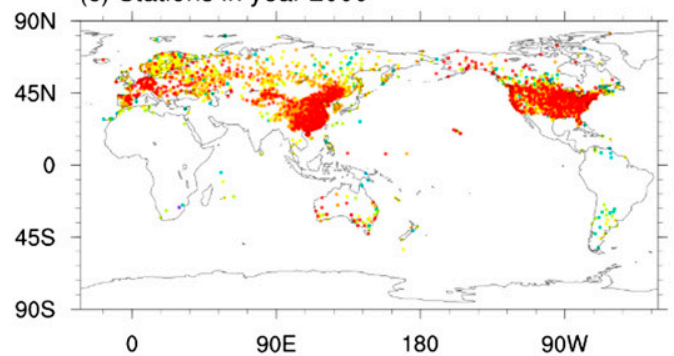

(e) GHCNDEX stations

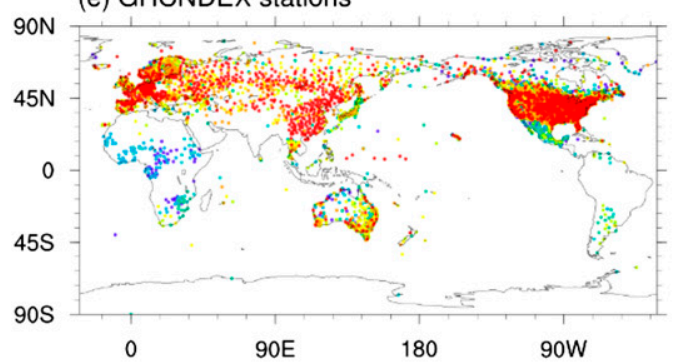

(g) HadEX2 stations

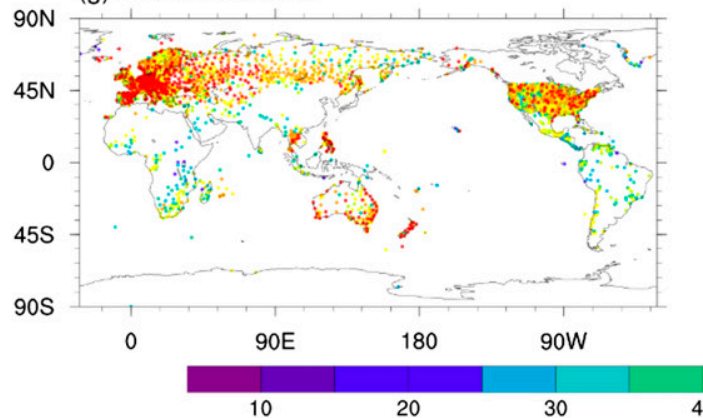

(b) Stations in year 1975

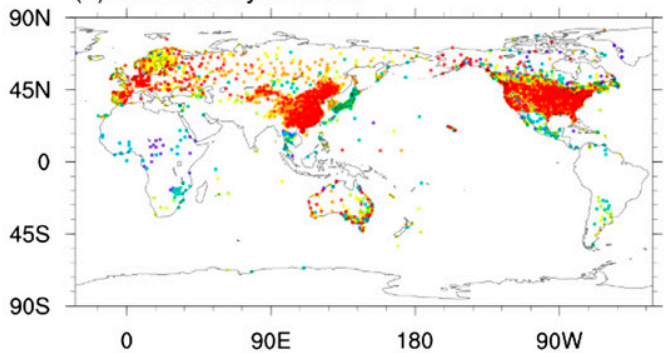

(d) Stations in year 2015

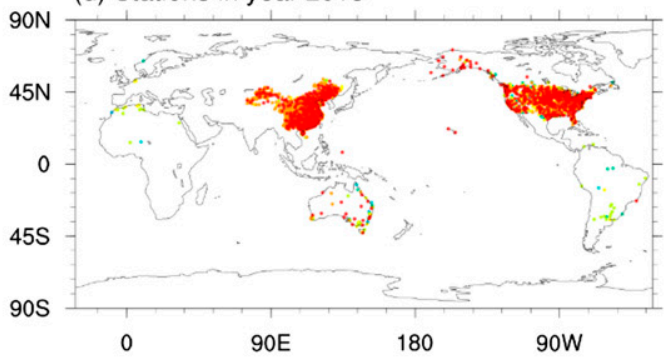

(f) GLSDT stations not in GHCNDEX

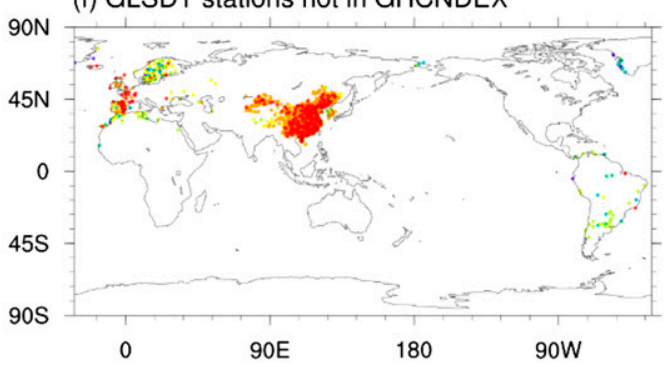

(h) GLSDT stations not in HadEX2

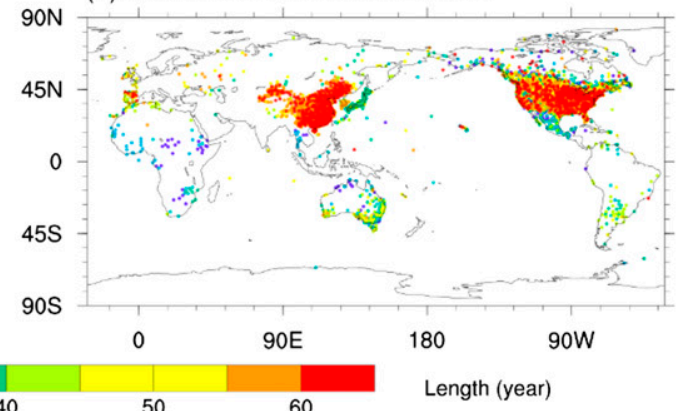

FIG. 2. (a)-(d) The stations distribution in the years 1955, 1975, 2000, and 2015. (e)-(h) The stations of GHCNDEX and HadEX2 (Donat et al. 2013a,b), and the corresponding temperature stations that are included only in GLSDT dataset but not in GHCNDEX and HadEX2, respectively. All the selected stations have at least 15 years of nonmissing data during the reference period 1961-90. The station record length refers to the length of nonmissing data from 1951 to 2015.

one time. It should be pointed out that, when calculating the four relative threshold indices (TN10p, TX10p, TN90p, and TX90p) by the definitions, there are artificial inhomogeneities at the beginning and end of the reference period, which make these indices unsuitable for monitoring and detecting long-term change; these can be effectively eliminated by using a bootstrap resampling procedure
(Zhang et al. 2005b). The climdex.pcic package (Bronaugh 2015) also adopted this bootstrap resampling method (Zhang et al. 2005b) in its algorithm for calculating the four relative threshold indices, which was also used by other researchers (Sillmann et al. 2013).

The time period of 1961-90 was considered as the climate reference period in this study. Regarding the 
calculation of the monthly indices, the number of missing values should be no more than 3 days in a month. For the calculation of the annual indices, not only the number of missing days should be no more than 3 days in a month, but also the number of missing days should be no more than 15 days in a year. The units of the four relative threshold indices (TN10p, TX10p, TN90p, and TX90p) were converted into days for better understanding.

\section{e. Analysis methods}

As the elevations of stations are variable and the spatial distribution of stations is uneven at different regions, it is unreliable to calculate the global average series through simple arithmetic average of the station data. Hence, the station temperature indices were first calculated for daily time series, and then the station indices values in the grids of $5^{\circ} \times 5^{\circ}$ latitudelongitude were averaged to obtain the grid indices values. The grid area-weighted average method developed by Jones and Hulme (1996) was used to calculate the global average extreme temperature indices series.

First, the annual/seasonal anomaly series relative to the reference period were calculated based on stations indices.

Second, we divided Earth's surface into $5^{\circ} \times 5^{\circ}$ latitude-longitude grids as mentioned above and averaged all the available station anomaly series within a grid box to get the grid anomaly series. The numbers and distribution of the grids with values varies among the different extreme temperature indices, but the blank grids are mostly distributed in Africa, Antarctic, and northern South America.

Finally, the global land average anomaly series was calculated using the gridbox area-weighted average method, with the weights being the cosines of the latitude of center of each grid with value (Jones and Hulme 1996). The global land average time series were calculated using only those gridcell series with at least $90 \%$ of data during 1951-2015.

Ordinary least squares (OLS) is widely used in the calculation of trends due to its simplicity and intelligibility. As OLS method is based on the hypothesis that the data have a Gaussian distribution, it is not robust to estimate trends when the data are not Gaussian distributed or there are outliers at the bound. Hence, the Shapiro-Wilk normality test (Royston 1982) was used to examine if the data series of a station comes from Gaussian distribution. The results showed that most of the indices violate the Gaussian assumption in varied extents (Fig. 1d). Additionally, serial correlation could increase the rejection rate of trend significant test (i.e., more significant trend would be obtained), which made the result unreliable (Von Storch and Navarra 1999). We calculated the partial autocorrelations of annual mean extremes indices series for each grid points for different lag $(\operatorname{lag}=1,2, \ldots, 12)$. As a result, we found that few partial autocorrelations for lag $>1$ are significant at the 5\% level. Therefore, the linear trend of a gridbox average mean anomaly time series was calculated using a modified Theil-Sen estimator (Sen 1968) that diminished the effect of lag-1 autocorrelation using an iterative prewhitening process (Zhang et al. 2000; Wang and Swail 2001), and the Mann-Kendall test (Mann 1945; Kendall 1955) was used to test the significance of trend at the $5 \%$ level. It was determined that, when the trends of gridcell series were estimated, the length of the time series should not be less than 40 years and the last year of the time series should not be earlier than 2000; otherwise the grid trend was set as missing values.

However, if a gridcell series of four absolute threshold indices [number of frost days (FD), number of summer days (SU), number of icing days (ID), and number of tropical nights (TR)] is all zero values, that is, no extreme events occurred in the entire time series, the trend of this gridcell series would still be calculated, but a cross mark would be added on the grid cell, which indicated that the trend estimate of this gridcell series was not being robust in statistics (Frei and Schär 2001). In addition to zero values, there is another situation in which the extreme events occurred every day of the year, that is, the saturated values $(365 / 366)$. For example, summer days and/or tropical nights of some stations near the equator may have saturated values $(365 / 366)$ in almost all years. We found that none of the stations have all saturated values in the entire time series, and only a few stations (3-5) whose ratio of saturated values to record length exceeds $90 \%$. So, the situation of saturated values would not be taken into account in this study.

In addition to the whole time period of 1951-2015, we also calculated and analyzed the trends of the extreme temperature indices for two subperiods of 1951-75 and 1976-2015 according to the change characteristics of these indices. Climatic seasons were applied to analyze the long-term change in seasonal mean extreme temperature indices. March, April, and May (MAM) were considered spring (autumn in Southern Hemisphere); June, July, and August (JJA) were considered summer (winter in Southern Hemisphere); September, October, and November (SON) were considered autumn (spring in Southern Hemisphere); and December, January, 
TABLE 2. Trend estimates for 12 global extreme temperature indices over the periods 1951-75, 1976-2015, and 1951-2015. Trends of at least $5 \%$ significance are shown in bold. The units of cold nights (TN10p), cold days (TX10p), warm nights (TN90p), and warm days (TX90p) were converted to days.

\begin{tabular}{|c|c|c|c|c|}
\hline \multirow[b]{2}{*}{ Index } & \multicolumn{4}{|c|}{ Trend } \\
\hline & $1951-75$ & 1976-2015 & 1951-2015 & Units \\
\hline Frost days (FD) & -0.83 & -2.31 & -1.96 & days decade ${ }^{-1}$ \\
\hline Summer days (SU) & -0.21 & 2.95 & 1.76 & days decade ${ }^{-1}$ \\
\hline Icing days (ID) & -0.50 & -0.83 & -0.96 & days decade ${ }^{-1}$ \\
\hline Tropical nights (TR) & 0.00 & 2.03 & 1.27 & days decade ${ }^{-1}$ \\
\hline Maximum $T_{\max }(\mathrm{TXx})$ & -0.08 & 0.25 & 0.13 & ${ }^{\circ} \mathrm{C}$ decade $^{-1}$ \\
\hline Maximum $T_{\min }(\mathrm{TNx})$ & -0.01 & 0.27 & 0.19 & ${ }^{\circ} \mathrm{C}$ decade $^{-1}$ \\
\hline Minimum $T_{\min }(\mathrm{TXn})$ & 0.07 & 0.40 & 0.28 & ${ }^{\circ} \mathrm{C}$ decade ${ }^{-1}$ \\
\hline Minimum $T_{\min }(\mathrm{TNn})$ & 0.05 & 0.52 & 0.40 & ${ }^{\circ} \mathrm{C}$ decade $^{-1}$ \\
\hline Cold nights (TN10p) & -0.97 & -3.64 & -4.01 & days decade ${ }^{-1}$ \\
\hline Cold days (TX10p) & -0.45 & -3.41 & -2.85 & days decade ${ }^{-1}$ \\
\hline Warm nights (TN90p) & 0.13 & 8.31 & 5.34 & days decade ${ }^{-1}$ \\
\hline Warm days (TX90p) & -1.75 & 6.07 & 3.95 & days decade ${ }^{-1}$ \\
\hline
\end{tabular}

and February (DJF) were considered winter (summer in Southern Hemisphere).

\section{Results}

For all the indices, the global land average anomaly series shows a significant (at the 5\% level) warming trend during the period 1951-2015. However, the change mainly occurred during the period 1976-2015. For most of the indices, the trend magnitude over the period 1951-76 is small and not significant statistically (Table 2). This temporal characteristic is consistent with the global land mean surface air temperature change as reported in previous works (Lawrimore et al. 2011; Jones et al. 2012). It should be also noted that the results are not strictly "global land average" because of the substantial spatial gap in some regions.

In the rest of this section, we mainly analyzed the absolute threshold indices (FD, SU, ID, and TR), relative threshold indices (TN10p, TX10p, TN90p, and TX90p), and extreme value indices (TXx, TNx, TXn, and TNn) to keep the length of this article within the limit (see Table 2 for descriptions of these indices).

\section{a. Absolute threshold indices}

Figure 3 shows the spatial distribution of trend and the global land average anomaly series for the four absolute threshold indices for the period 1951-2015.

In the perspective of spatial distributions of trends, the frequency of frost days was decreasing in most parts of the world, with Europe and Asia decreasing more than the other regions and North America and Australia decreasing modestly (Fig. 3a). However, the frequency of the frost days of a few grid boxes in southern Europe, North America, and the southern part of South America were increasing, although the upward trends were mostly insignificant. The frequency of summer days was increasing in most parts of the global land, and the midlatitude zone of the Northern and Southern Hemispheres is the most obvious area for warming in summer; in eastern and central North America, however, the frequency of summer days was decreasing (Fig. 3b). The frequency of icing days was decreasing in the most regions of the world, but the eastern, central, and southern parts of the United States witnessed an increasing trend (Fig. 3c). The frequency of tropical nights was also increasing in the most parts of the world, despite a decreasing trend that could be seen in a small part of the central United States (Fig. 3d).

The global land average of frost days decreased over the entire study period, with the most rapid decline occurring after the mid-1970s during which the anomaly value of the index was mainly negative. Frost days were relatively lower in 1990, 1998, 2007, and 2015, and the lowest values occurred in 2015 (Fig. 3a). The change pattern of icing days is similar to that of frost days, but the latter has a greater trend in most parts of the world (Table 2). Before the mid-1970s, there was almost no obvious trend in summer days, but the global average index series increased rapidly since the mid1970s. Since the mid-1970s, except for the obvious negative anomalies in 1983-85 and 1992-93, all the other years registered positive anomalies, with the highest positive values appearing in the last decade. The lowest level occurred in 1992-93, when the stratospheric aerosol optical depth was at its peak due to the influence of the eruption of the Mount 
(a) Frost Days
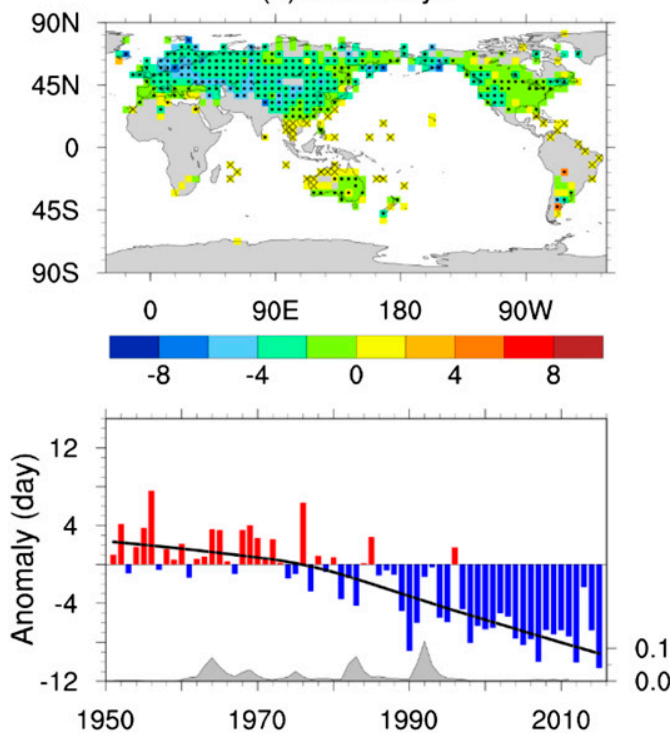

(c) Icing Days
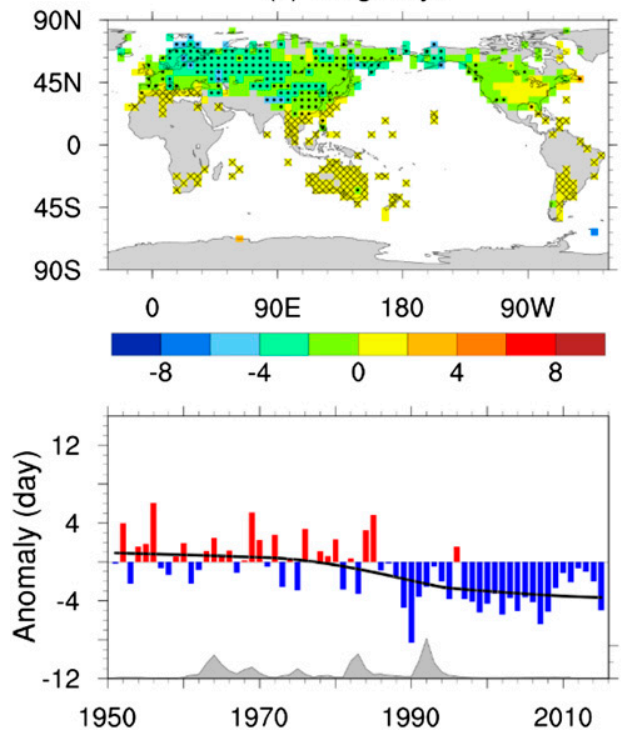

(b) Summer Days
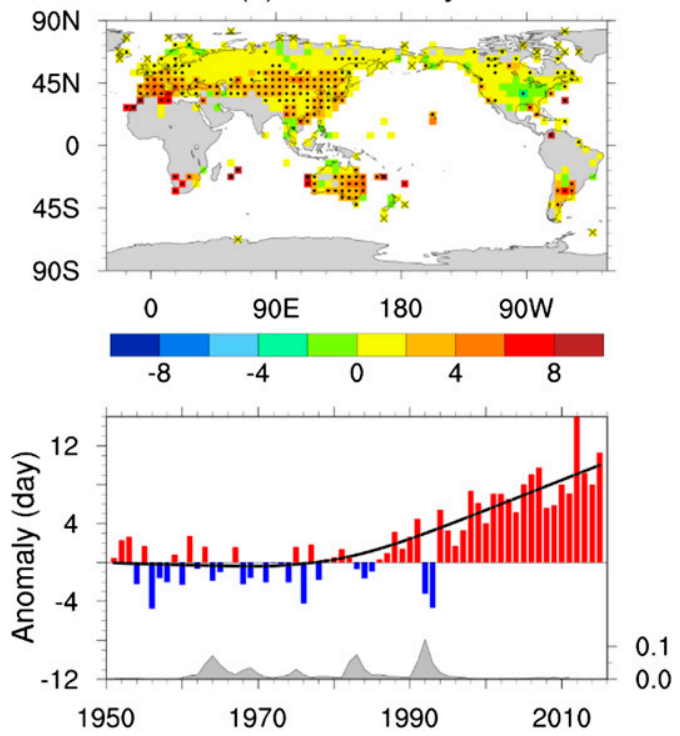

(d) Tropical Nights
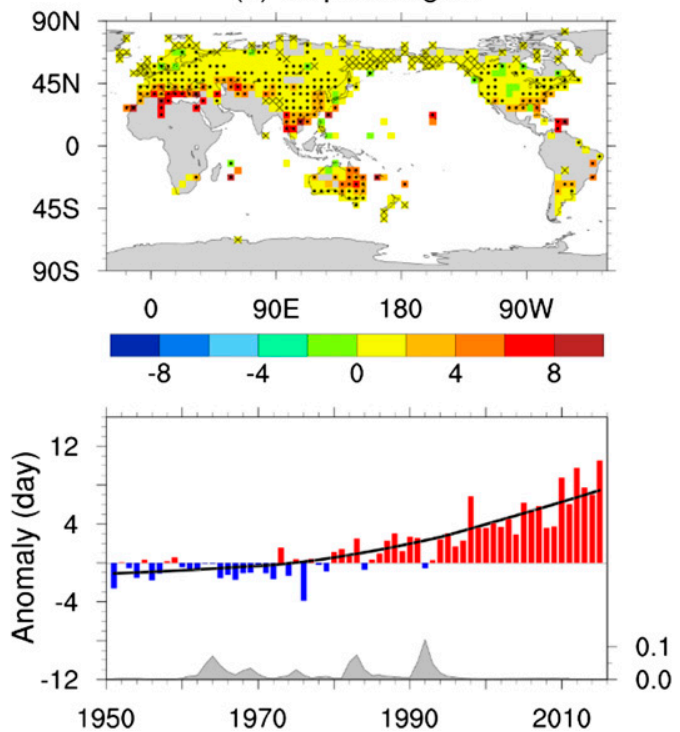

FIG. 3. Trends distribution of grid average annual extreme temperature indices (day decade ${ }^{-1}$ ) and global land average time series of annual anomalies relative to the reference period (1961-90) average (day) over 1951-2015 for (a) frost days (FD), (b) summer days (SU), (c) icing days (ID), and (d) tropical nights (TR). Trends were calculated only for the grid boxes that have at least 40 years of data during the study period and the last year of the data does not occur before 2000 . The global average time series were calculated using only the gridcell series that have at least $90 \%$ of data during 1951-2015. Stippling indicates the gridcell trends are significant at the 5\% level. Cross marks indicate the gridcell series with only zero values, i.e., no extreme events occurred in the entire time series. The black smooth curves on the bar chart were obtained by using the locally weighted scatter smoothing (LOWESS) method (Cleveland 1979). Gray shading presents the time evolution of global average aerosol optical depth series at $550 \mathrm{~nm}$ (Sato et al. 1993).

Pinatubo volcano in 1991. When the stratospheric aerosol optical depths were relatively high, the summer days were usually fewer. The change of tropical nights is similar to summer days, but the trend magnitude of the former is generally greater.
Therefore, all of the four absolute threshold indices indicate warming trends during the study period 1951-2015 (i.e., frost days and icing days decreased, and summer days and tropical nights increased), but the warming of these indices mainly occurred after the mid-1970s. No 
(a) Cold nights
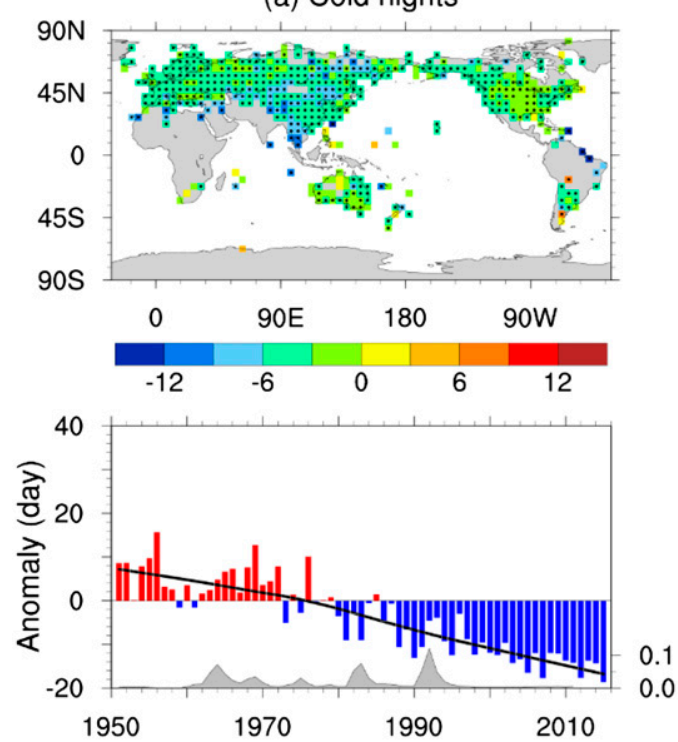

(c) Warm nights
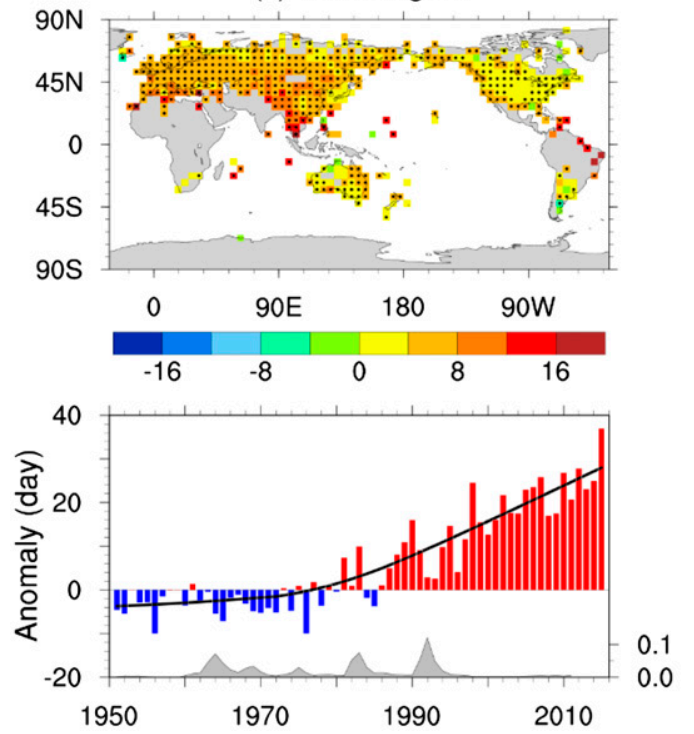
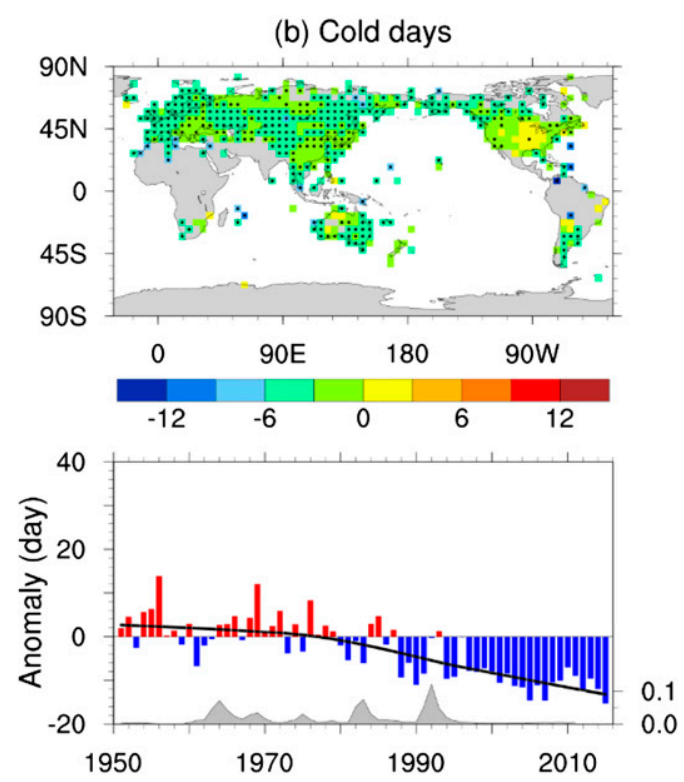

(d) Warm days
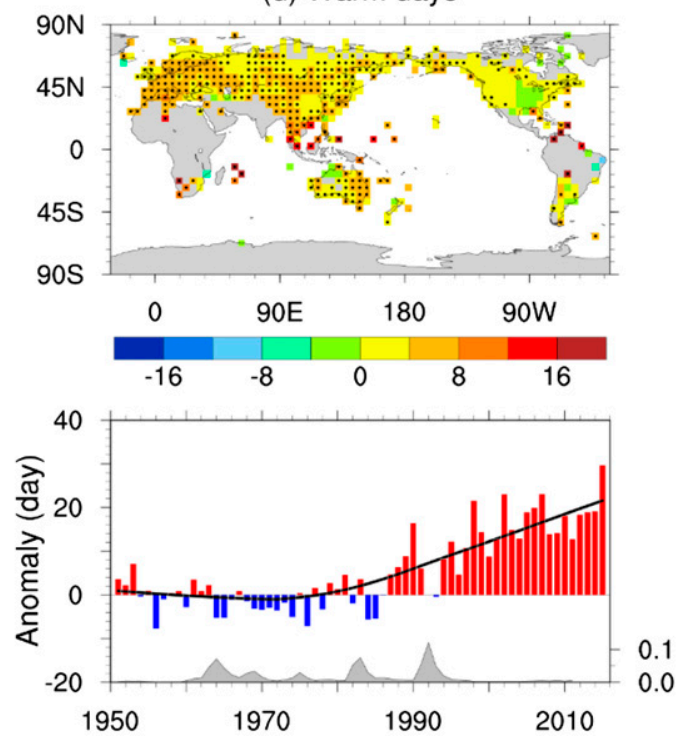

FIG. 4. As in Fig. 3, but for relative threshold indices: (a) cold nights (TN10p), (b) cold days (TX10p), (c) warm nights (TN90p), and (d) warm days (TX90p). The units of these indices were converted to days.

statistically significant change occurred for these indices before the mid-1970s.

\section{b. Relative threshold indices}

Figure 4 presents the linear trends patterns and global land average series of four relative threshold indices (cold nights, cold days, warm nights, and warm days). In view of the spatial distributions of the trends, cold nights and warm nights showed a good spatial consistency. Except for a few grid boxes, the regions of the continents experienced a warming trend, that is, the cold nights were decreasing and warm nights were increasing in frequency, cold nights decreased more in Eurasia than other continents, and similarly, warm nights also increased more in Eurasia than other continents.

At the same time, cold days showed a decreasing trend and warm days showed an increasing trend in the most parts of the continents. However, the central and southern parts of the United States presented a spatial inconsistency with the rest of world. In these areas, the cold days were increasing and warm days were decreasing in frequency, forming the so-called warming 
hole (Pan et al. 2004), although the trends of these areas were not significant statistically. Similarly, the magnitude of trends in these indices was larger in Eurasia than in the other continents including North America.

Global land average extreme cold indices (cold days and cold nights) were decreasing in frequency, extreme warm indices (warm days and warm nights) were increasing in frequency, and the change magnitude of extreme cold indices was smaller than that of the extreme warm indices. It was notable that, before the mid-1970s, the extreme cold indices and extreme warm indices were relatively stationary and the trends were also not significant statistically (Table 2). However, these indices changed quickly, and the trends were also statistically significant after the mid-1970s (Table 2). The last year (2015) of the study period was the year with the highest frequency of extreme warm events and the lowest frequency of extreme cold events in the last 65 years.

\section{c. Extreme value indices}

As shown in Fig. 5, the four extreme value indices (TXx, TNx, TXn, and TNn) show a warming trend in most parts of the world, but the trends of the indices related to the daily maximum temperature (TXX and TXn) are spatially more variable than the indices related to daily minimum temperature ( $\mathrm{TNx}$ and $\mathrm{TNn}$ ). A cooling trend of TXx could be seen once again in eastern United States. Although the trends of TXn in central and southern United States are negative, they are not significant at the 0.05 level. The cold extreme events (TXn and TNn) experienced a larger warming trend in mid- and high-latitude regions of Northern Hemisphere than in other regions.

The global land average time series of four extreme value indices did not change significantly before the mid-1970s (Table 2), but experienced a rapid increase after the mid-1970s, which is consistent with the changes in the other extreme temperature indices.

\section{d. Seasonal changes}

In this section, we present the seasonal analysis results for only the cold nights (TN10p; Fig. 6) and warm days (TX90p; Fig. 7) because of the limited length of the paper.

All seasons have warmed during the study period 1951-2015 in terms of changes in the two indices. The frequency of cold nights was decreasing, the frequency of warm days was increasing, and the linear trends of the two indices are significant statistically (Figs. 6 and 7 and Table 3). However, there was a shift near the middle of 1970s. Before that time, almost all seasons (except for the cold nights in MAM) changed slowly, and the trend was found to be insignificant statistically; after the mid-1970s, the changes were faster, and the trends were found to be significant statistically. The cold nights in MAM exhibited a faster decreasing trend before the mid-1970s than during the later period, indicating an earlier warming of nighttime in boreal spring. At the same time, warm days had a small decreasing trend in all seasons before the mid-1970s, showing that there was a tendency to become cooler during the daytime, although it was not significant statistically.

The signal of the Mount Pinatubo volcano eruption in 1991 seemed strong in the global land annual anomaly series of warm days in JJA and SON, but was not so obvious in other seasons (Fig. 7). The boreal autumn and summer signal of the eruption was also notable, to a less extent, in the annual anomaly series of cold nights in 1992-93.

In view of spatial distribution, cold nights (Fig. 6) in Asia (especially in DJF) have decreased more than those in any other regions, while the decrease was relatively small in the United States, where it even witnessed an increasing trend in DJF (Fig. 6d), though the trend are not significant statistically. This is consistent with that reported in Alexander et al. (2006) for cold nights.

In MAM, warm days have increased more in Asia and Europe than in the other regions, while in JJA, the daytime warming mainly occurred in southern Europe and northern Africa, central and Southeast Asia, and Australia. The frequency of warm days decreased in the central and southern part of the United States in all the four seasons, with the decrease being most remarkable in JJA. An area with little change in warm days can be seen in eastern China in summertime.

\section{Discussion}

\section{a. Comparison with previous studies}

Overall, our findings in this paper are similar to the previous analyses investigating global land changes in temperature extremes (Easterling 2000; Frich et al. 2002; Alexander et al. 2006; Caesar et al. 2006; Donat et al. 2013a,b). The trends of the HadGHCND and GHCNDEX datasets over the periods 1951-2011 were reported in Donat et al. (2013b). For the sake of comparison, we also calculated the trend of each index over the period 1951-2011, as shown in Table 4. In general, the change magnitude of the extreme cold indices is greater than the change magnitude of the extreme warm indices in all of these datasets. For extreme value indices and relative threshold indices, the linear trends estimated in this study show substantial similarity to those estimated 
(a) TXX
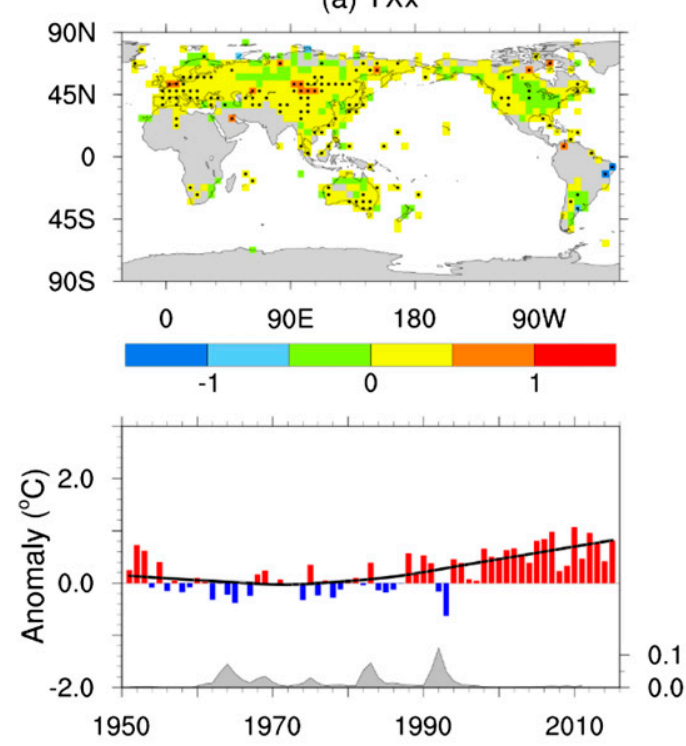

(c) TXn
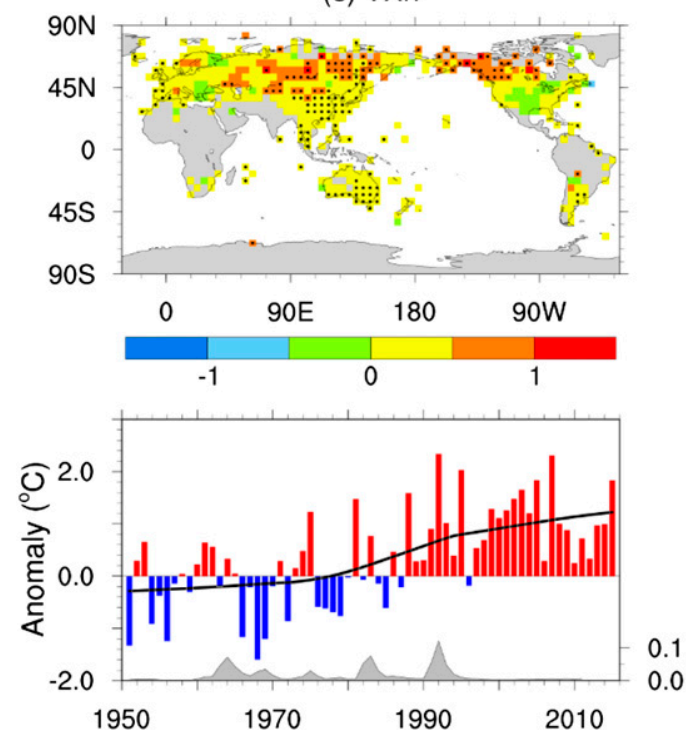

(b) $\mathrm{TNx}$
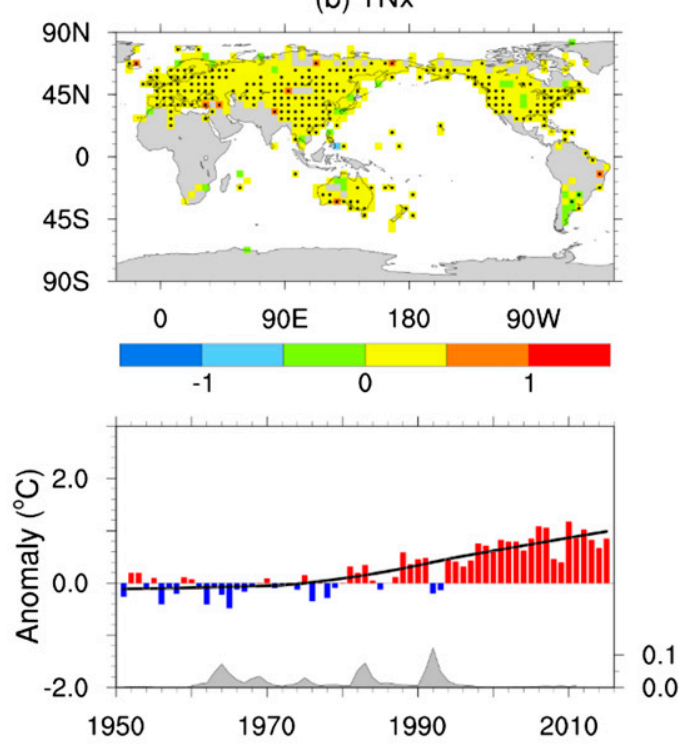

(d) $\mathrm{TNn}$
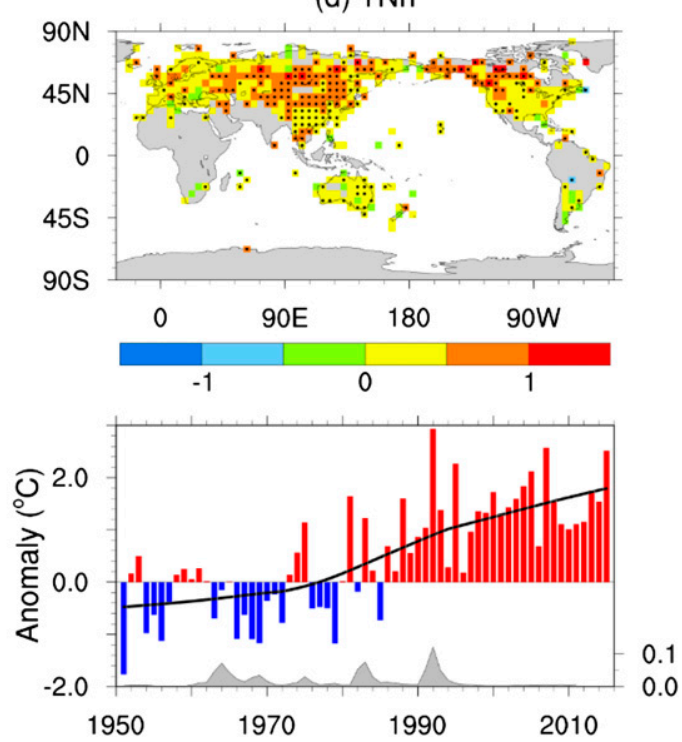

FIG. 5. As in Fig. 3, but for indices (a) maximum $T_{\max }(\mathrm{TXx})$, (b) maximum $T_{\min }(\mathrm{TNx})$, (c) minimum $T_{\max }(\mathrm{TXn})$, and (d) minimum $T_{\min }(\mathrm{TNn})$.

in the previous studies, with most of our estimates of trend values for relative threshold indices standing between those based on the HadGHCND (Caesar et al. 2006; Donat et al. 2013b) and GHCNDEX (Donat et al. 2013b) datasets.

There are some minor differences of trends among the three datasets, most probably due to the fact that 1) the different criteria had been used for choosing stations and the resulting different data coverage in the continents, 2) the different methods had been used to create grid averages from station data, or 3) the extreme temperature indices had been calculated from stations and then gridded (GHCNDEX) or from gridded daily data to calculate grid indices series (HadGHCND) (X. Zhang et al. 2011). In this research, the temperature indices series were first calculated from station daily time series, and then the station indices values were averaged to obtain the gridded fields. The differences in the calculation order also may affect the results in certain extent and their interpretation (X. Zhang et al. 2011; Avila et al. 2015). Dunn et al. (2014) investigated the uncertainties in global gridded datasets of climate 
(a) MAM
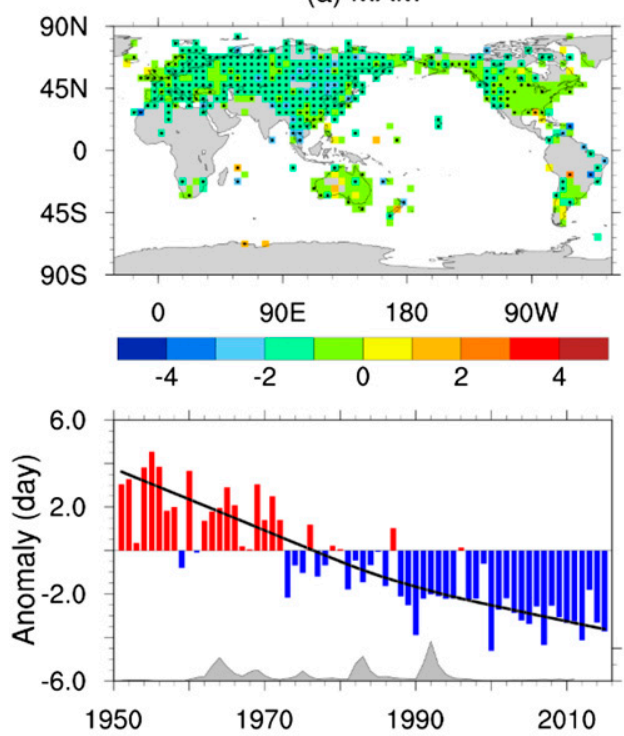

(c) SON
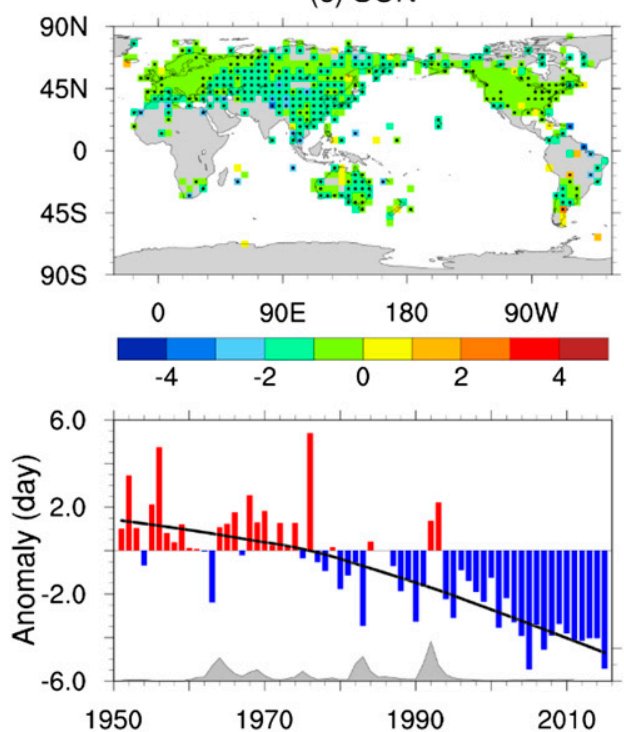

(b) JJA
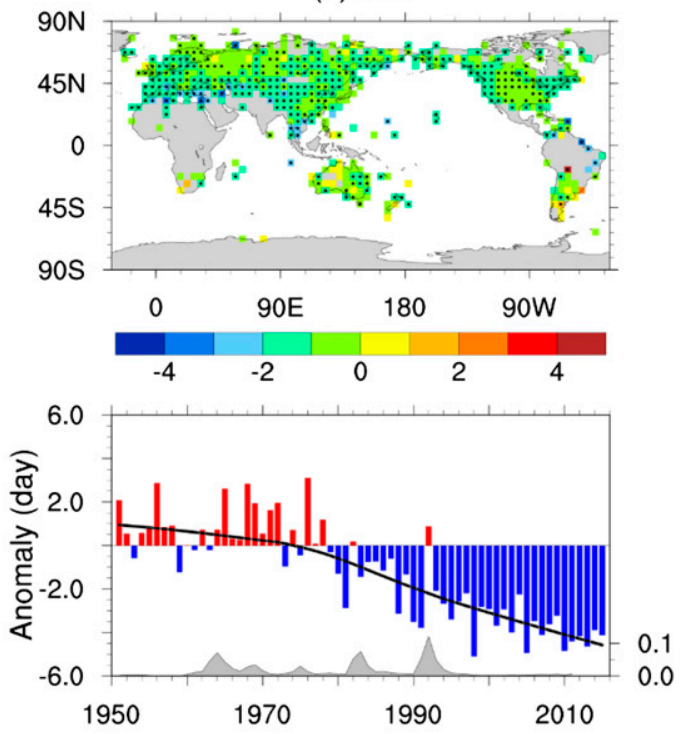

(d) DJF
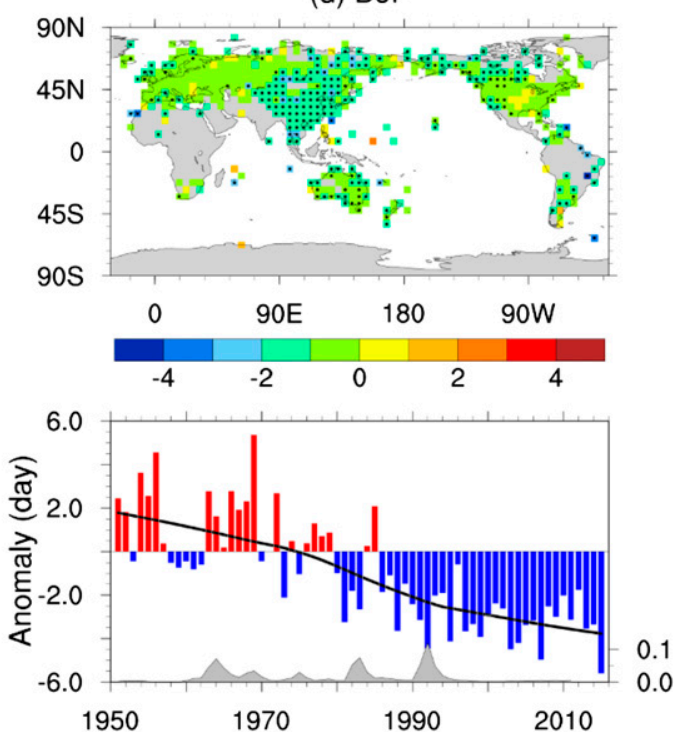

FIG. 6. As in Fig. 4a, but for the seasonal results of cold nights (TN10p): (a) March-May, (b) June-August, (c) September-November, and (d) December-February.

extremes and found that the global land time series of the indices were only slightly affected by "parametric uncertainty" (the changes of parameters within the analytical framework), but were largely affected by "structural uncertainty" (the changes of overall analytical framework). The structural uncertainty can be estimated by having multiple independent teams analyze the same dataset using distinct methods (Hartmann et al. 2013). The trend 1.59 days decade ${ }^{-1}$ of summer days in this study is significantly greater than the trend of GHCNDEX and HadGHCND, which may be caused by structural uncertainty because a similar trend 1.29 days decade d $^{-1}$ of summer days can be obtained by calculated the GHCNDEX dataset using the same procedures used in this study.

Some extreme events (frost days, summer days, icing days, and tropical nights) may never occur in certain regions. For example, frost days and icing days occur rarely in low-latitude regions, and summer days and tropical nights occur rarely in high latitudes and high-elevation regions. Therefore, if the grid series of four absolute threshold indices is all zero values, that 
(a) MAM
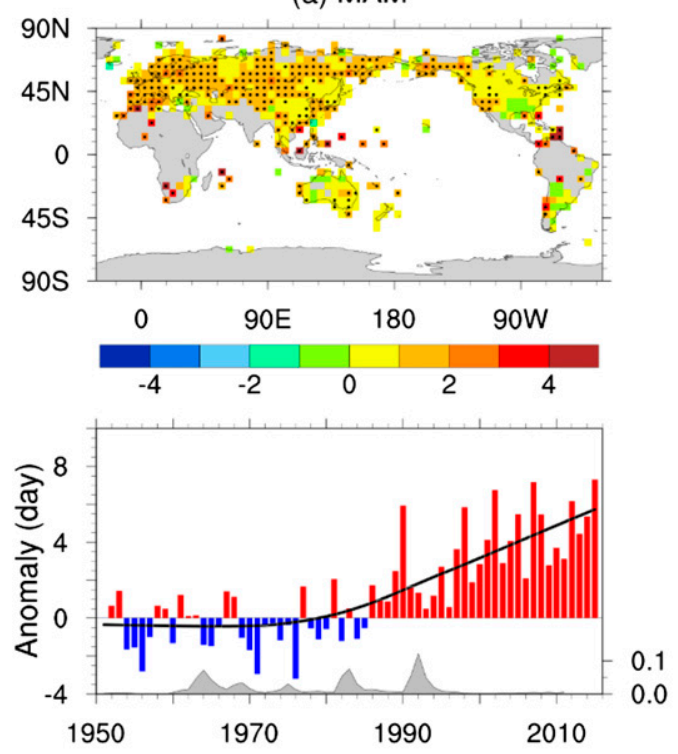

(c) SON
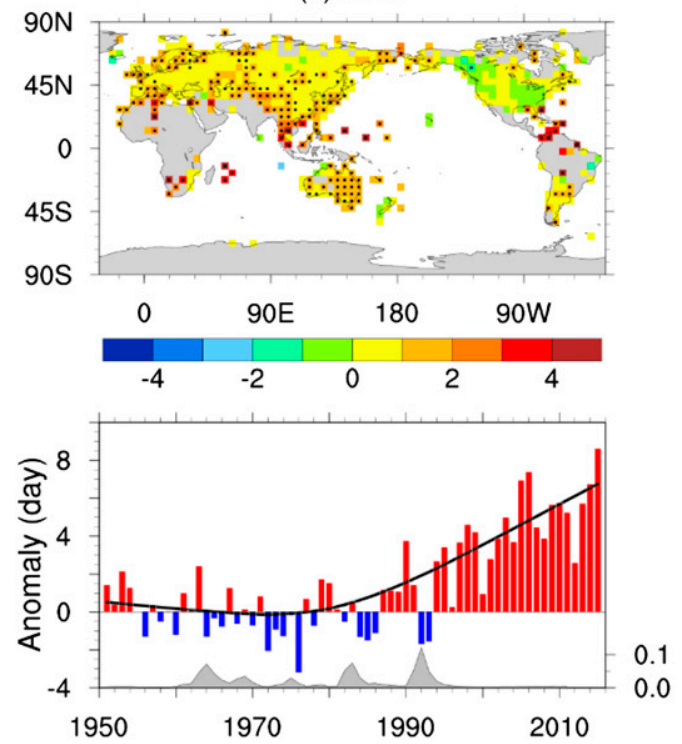

(b) JJA
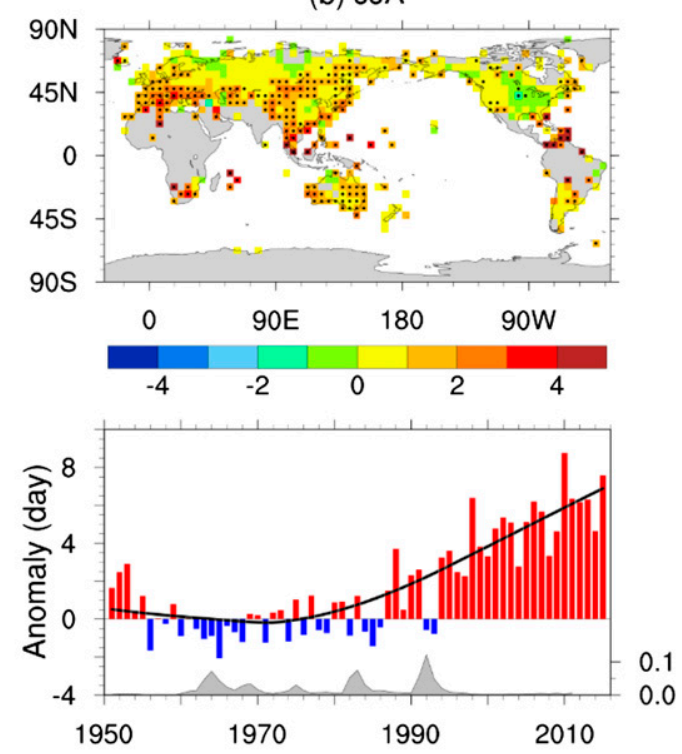

(d) DJF
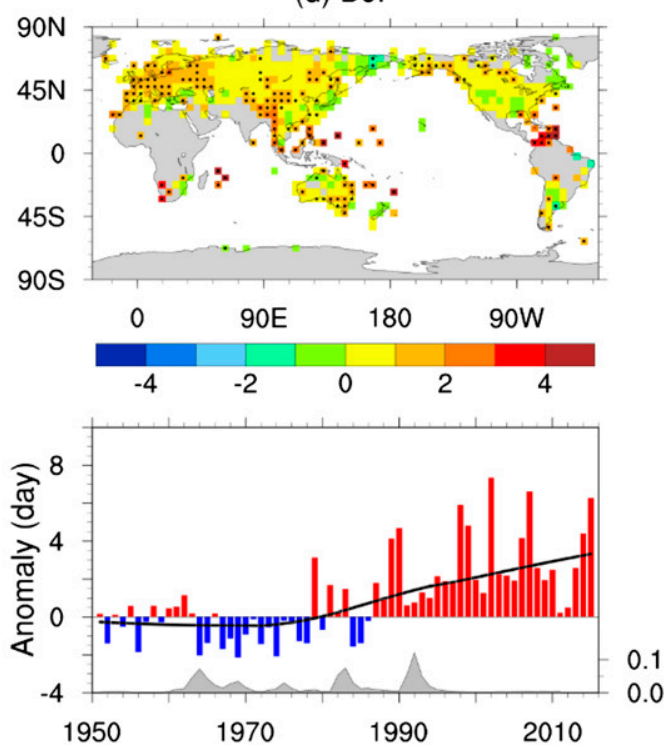

FIG. 7. As in Fig. 4d, but for the seasonal results of warm days (TX90p): (a) March-May, (b) June-August, (c) September-November, and (d) December-February.

is, no extreme events occurred in the entire time periods, the trend of this grid cell would still be calculated, but a cross mark would be added on the grid cell, which indicated that the trend estimate of this grid series was not being robust statistically (Frei and Schär 2001). In this study, the global land average time series of the four absolute threshold indices were calculated using all the gridcell series (including all zero values series) that have at least $90 \%$ data during 1951-2015, which results in a more consistent global land averaged trend with previous works (e.g., GHCNDEX and
HadGHCND), but a generally significantly larger trend of global land averaged series can be obtained when a more rigorous restriction (lower tolerance for the number of zero values in the indices series) were applied in the spatial average estimate of trend. The latter procedure would reduce the size of the sampling area (fewer grid boxes being sampled for this purpose) and narrows the extents calculated. Further experiments are needed to understand which procedure is more robust in statistics and spatial representativeness. 
TABLE 3. Linear trends in temperature extremes indices during 1951-75, 1976-2015, and 1951-2015. The units of cold nights (TN10p), cold days (TX10p), warm nights (TN90p), and warm days (TX90p) were converted to days. Trends of at least 5\% significance are shown in bold.

\begin{tabular}{|c|c|c|c|c|c|}
\hline & & \multicolumn{4}{|c|}{ Trend } \\
\hline \multicolumn{2}{|l|}{ Index } & $1951-75$ & $1976-2015$ & $1951-2015$ & Units \\
\hline \multirow[t]{4}{*}{ Cold nights (TN10p) } & MAM & -1.40 & -0.84 & -1.18 & days decade ${ }^{-1}$ \\
\hline & JJA & 0.14 & -0.89 & -0.97 & days decade ${ }^{-1}$ \\
\hline & SON & -0.32 & -1.19 & -1.03 & days decade ${ }^{-1}$ \\
\hline & DJF & -0.29 & -0.92 & -0.98 & days decade ${ }^{-1}$ \\
\hline \multirow[t]{4}{*}{ Warm days (TX90p) } & MAM & -0.20 & 1.70 & $\mathbf{1 . 0 3}$ & days decade ${ }^{-1}$ \\
\hline & JJA & -0.49 & 2.00 & 1.11 & days decade ${ }^{-1}$ \\
\hline & SON & -0.70 & 1.93 & 1.10 & days decade ${ }^{-1}$ \\
\hline & DJF & -0.39 & 1.07 & 0.69 & days decade ${ }^{-1}$ \\
\hline
\end{tabular}

This paper made a preliminary seasonal analysis for cold nights and warm days, but the range of change magnitude of seasonal results of this study differ significantly from the study of Alexander et al. (2006). For example, the value of the cold nights time series in this study varies from -6 to 6 , but the study of Alexander et al. (2006) is from -20 to 20. In this study, cold nights and warm days were first calculated on basis of monthly percentages, then the monthly percentages were converted to monthly days, and at last, the monthly values (days) were summed to obtain the seasonal and annual values (days). The annual values (days) are the sum of four seasonal values (days). Consequently, the range of change magnitude of annual cold night and warm day series should be greater than the seasonal ones. In Alexander et al. (2006); however, the magnitudes of annual and seasonal change of the two indices series are similar. This difference may also be related to the different grid coverage, and the procedures on how the anomalies were calculated and how the data were averaged.

\section{b. "Warming hole" in the United States}

Over the past 65 years, most regions of the world have experienced warming trends, but the central and southeastern part of the United States experienced no significant change or a slight cooling trend, characterized by an increase in cold extremes indices and a decrease in warm extremes indices especially for those related to the daily maximum temperature. The seasonal trends of warm days (Fig. 7) showed that the cooling mainly appeared in the daytime during boreal summer and autumn (i.e., JJA and SON), but in the other two seasons (MAM and DJF), only a few grid boxes experienced a cooling trend in these areas and all of the trends were not statistically significant.

Folland et al. (2001) found that central United States showed a cooling trend over the period 1976-2000 for the summer season. Pan et al. (2004) named this cooling

TABLE 4. Trend estimates for global average series of 12 extreme temperature indices over the periods 1951-2011. Trends of at least $5 \%$ significance are shown in bold. To compare with HadGHCND (Caesar et al. 2006; Donat et al. 2013b) and GHCNDEX (Donat et al. 2013b), the units of cold nights (TN10p), cold days (TX10p), warm nights (TN90p), and warm days (TX90p) were not converted to days here.

\begin{tabular}{|c|c|c|c|c|}
\hline \multirow[b]{2}{*}{ Index } & \multicolumn{4}{|c|}{ Decadal trend: 1951-2011 } \\
\hline & GHCNDEX & HadGHCND & GLSDT & Unit \\
\hline Frost day (FD) & -1.80 & -1.72 & -1.95 & days decade ${ }^{-1}$ \\
\hline Summer day (SU) & 0.47 & 0.54 & 1.59 & days decade ${ }^{-1}$ \\
\hline Icing days (ID) & -1.23 & -1.18 & -1.09 & days decade ${ }^{-1}$ \\
\hline Tropical night (TR) & 0.91 & 1.05 & 1.13 & days decade ${ }^{-1}$ \\
\hline Maximum $T_{\max }(\mathrm{TXx})$ & 0.11 & 0.10 & 0.12 & ${ }^{\circ} \mathrm{C}$ decade ${ }^{-1}$ \\
\hline Maximum $T_{\min }(\mathrm{TNx})$ & 0.12 & 0.17 & 0.19 & ${ }^{\circ} \mathrm{C}$ decade ${ }^{-1}$ \\
\hline Minimum $T_{\min }(\mathrm{TXn})$ & 0.28 & 0.27 & 0.29 & ${ }^{\circ} \mathrm{C}$ decade ${ }^{-1}$ \\
\hline Minimum $T_{\min }(\mathrm{TNn})$ & 0.45 & 0.39 & 0.40 & ${ }^{\circ} \mathrm{C}$ decade ${ }^{-1}$ \\
\hline Cold night (TN10p) & -1.09 & -1.26 & -1.09 & $\%$ decade ${ }^{-1}$ \\
\hline Cold day (TX10p) & -0.67 & -0.86 & -0.76 & $\%$ decade $^{-1}$ \\
\hline Warm night (TN90p) & 1.17 & 1.79 & 1.33 & $\%$ decade $^{-1}$ \\
\hline Warm day (TX90p) & 0.80 & 1.14 & 0.95 & $\%$ decade $^{-1}$ \\
\hline
\end{tabular}


area in summer as "warming hole" and argued that the changes in low-level atmospheric circulation might have supplied more soil moisture in summer, which would increase the summer evapotranspiration and repress the daily maximum temperatures. Kunkel et al. (2006) found that central United States temperature and North Atlantic sea surface temperatures are positively correlated, and central United States temperature and central equatorial Pacific sea surface temperature are negatively correlated. The long-term cooling in the North Atlantic and warming in the central equatorial Pacific were thus regarded as the main reason for the summer cooling in the central and eastern United States. Leibensperger et al. (2012) found that radiative forcing of U.S. anthropogenic aerosols caused the daily maximum temperature of summer and autumn in the central United States to decline in the period 1970-90. The cooling effect of anthropogenic aerosol reduced surface evaporation, which reduced the precipitation on the east coast of the United States, but increased the air moisture flowing northward from the Gulf of Mexico that would increase the cloud cover and precipitation in the central United States (Leibensperger et al. 2012).

Our analysis results showed that the cooling of the United States mainly appeared in the daytime of boreal summer and autumn supports the claim that the weakening daytime solar radiation, or the interaction between solar radiation and soil moisture, may have played an important role in forming the cooling area in the last 65 years. The declining solar radiation may have been caused by the increasing cloudiness rather than increasing aerosol concentration, because aerosol emission in the region had been controlled to a large degree ( $\mathrm{Li}$ et al. 2011). A smaller cooling area or no significant change area is also visible in eastern China during boreal summer, and it may have been caused by the daytime weakening of solar radiation most probably related to the combined effect of increasing aerosol emission and cloudiness, with the rising aerosol concentration playing a larger role in northern part of the region (Qian et al. 2003; Zhang et al. 2007; Ding and Ren 2008; Li et al. 2011).

\section{c. Influence of stratospheric aerosol}

Earth's radiation balance was affected by aerosols that absorb upward terrestrial thermal radiation and reflect sunlight to space. The stratospheric aerosol optical depth is one of the principle parameters affecting the Earth surface climate (Lacis et al. 1992; Sato et al. 1993). Figures 3-7 show that the stratospheric aerosol optical depth might have an important impact on interannual variability of the extreme temperature indices. When the stratospheric aerosol optical depth

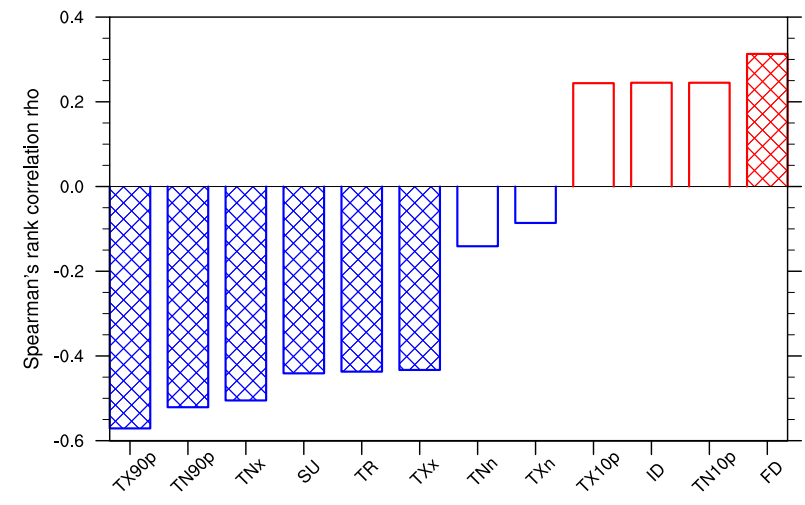

FIG. 8. The Spearman's rank correlation (rho) between extreme temperature indices and stratospheric aerosol optical depth at $550 \mathrm{~nm}$. Correlations (rho) of at least $5 \%$ significance are filled with grid lines.

reached a peak, the frequency of cold extreme events would increase, and the frequency of warm extreme events would decrease, especially for the daytime extremes of boreal summer and autumn. A good example is the abnormally low level of annual and summer daytime warm event frequency in 1992-93 following the Mount Pinatubo volcano eruption in 1991 (Figs. 3-7).

We calculated the Spearman's rank correlation (rho) (Best and Roberts 1975; Hollander and Wofle 1973) between global land average extreme indices and the stratospheric aerosol optical depth after removing the linear trends. As shown in Fig. 8, it can be clearly seen that the stratospheric aerosol optical depths were positively correlated with cold extreme threshold indices (TN10p, ID, TX10p, and FD) and were negatively correlated with warm extreme threshold indices (TX90p, TN90p, SU, and TR), and the absolute magnitude of correlation coefficient with warm extremes indices (TX90p, TN90p, SU, and TR) are larger and are more significant statistically. The higher the stratospheric aerosol optical depth, the cooler the daytime surface air during warm seasons of Northern Hemisphere. The indices associated with temperature extreme values (TNx, TXx, TNn, and TXn) were all negatively correlated with stratospheric aerosol optical depth regardless it is warm indices or cold indices, and the indices of TNx and TXx (warm indices) have a more significant negative correlation with aerosol optical depth than the indices of TNn and TXn (cold indices). The reason for the association is that more stratospheric aerosols would absorb and reflect more solar radiation in stratosphere, leading to less radiation received in the surface and an abnormally cooling condition during daytime. Of course, the interannual to decadal variability is the result of the interaction of many factors including stratospheric aerosols. 


\section{d. Uncertainty of trend estimates}

In this study, the homogeneity test was conducted by using RHtestsV4 (Wang 2008a,b; Wang and Feng 2013) software and the station series identified as inhomogeneous were discarded. It is inevitable to exclude some potential natural climate shifts because there is no further analysis for these step changes due to the lack of metadata and the observations from densely stations. To avoid this "false exclusion" as much as possible, a higher confidence threshold $99.99 \%$ was used for homogeneity testing. Meanwhile, this method was designed to detect only step changes (sudden shifts in the mean) in the data series but not to detect gradual temperature changes, including those related to urbanization effects and gradual changes in the local observing environment.

It is well known that the urban heat island effect can cause the urban surface air temperature to be higher than the suburb or rural areas. Meanwhile, a large number of stations are located in or near urban areas, despite the urban areas only accounting for a small portion $(<1 \%)$ of the global land. As a result, if these observations of temperature at urban stations are used to analyze mean temperature and extreme temperature change, the warming trends can be overestimated not only for individual stations and grid boxes but also for the regional average series (Ren 2015).

Urbanization effects differ from region to region due to the different speed of urban development and the specifically designed locations of the observational sites in different countries. It is possible that, in developed areas, the urban infrastructure of well-established cities did not expand in the last decades. Although the stations located in a city center observed a warmer climate than those located in rural stations, the trend for the decades might be similar, because the influences on urban temperature have not changed over this period (Peterson 2003; Jones et al. 2008; Ren 2015). However, in developing areas, such as the mainland of China and western Asian countries, the urbanization effect on temperature trends might not be negligible due to the rapid urban development (Zhou et al. 2004; Ren et al. 2008; Zhou and Ren 2011; Li and Huang 2013; Ren and Zhou 2014; Sun et al. 2016). It is unclear for the time being to what extents the urbanization processes had affected the estimated trends of the global land average annual and seasonal mean extreme temperature indices as reported in this paper. An attempt could be made to tackle this issue in the future.

On a regional scale, however, there had been a couple of studies examining the urbanization effect on extreme temperature trends (Zhou and Ren 2009, 2011; L. Zhang et al. 2011; Ren and Zhou 2014). Zhou and Ren (2011) found that urbanization effect on long-term trends of the $T_{\text {min }}$-related extreme temperature indices of national stations in North China was rather large and statistically highly significant for the period 1961-2008, and the urbanization contributions for the regional average annual series of frost days, tropical nights, cold nights, and warm nights reached $45 \%, 64 \%, 44 \%$, and $48 \%$ respectively. Taking mainland of China as a whole, the urbanization also has a statistically significant effect on the above-mentioned four extreme temperature indices series of national stations during the same time period, and the urbanization accounts for more than $10 \%$, $38 \%, 17 \%$, and $26 \%$ of the overall trends, respectively (Ren and Zhou 2014).

Therefore, it is possible that the global land average annual and seasonal extreme temperature indices series over the last 65 years contain some degree of urbanization effects, in particular in developing regions. However, the urbanization may have little effects for the other regions when compared to those found for the mainland of China, mainly due to the relatively slow development of urban areas in the regions outside East Asia in the last 65 years.

Another major uncertainty source is the data gaps in different periods in Africa, India, and South America. The number of available temperature stations reached the maximum in the late 1970s and started to decline since then, as shown in Figs. 1a and 1c. Furthermore, these data gaps were changing over time, leading to a temporal change in the spatial coverage of observations. These would make the accurate assessment and robust detection of extreme temperature change in these regions particularly difficult, and also result in another systematic bias in the estimate of the global land average extreme temperature indices trends. This bias needs to be investigated in the following works. It is generally deemed, however, that the bias in the global land average annual mean surface air temperature series due to the data coverage is small compared to the overall trends estimated for various time periods of the last century (Hansen et al. 2006; Lawrimore et al. 2011; Jones et al. 2012).

However, the effect of the daily temperature data coverage and its change with time, in particular in Africa, southern parts of Asia, Arctic regions, and South America, on trend estimates of global land average extreme temperature indices still needs to be examined. As there are not any daily temperature data in most grid boxes in Africa and South America, all the extreme temperature indices series could not be calculated. Before the influence of data coverage on the estimated trends of extreme temperature indices is addressed, it is reasonable to assume that the current global land 
analysis results, including those reported in this paper, heavily reflect the long-term changes of average extreme temperature indices of Northern Hemispheric continents, especially those of the data-dense Europe, East Asia, and North America.

\section{Conclusions}

In this paper, we presented a new analysis of global land extreme temperature indices changes based on an integrated global land surface daily temperature dataset (GLSDT-V1.0) recently developed by the National Meteorological Information Center, CMA. Our main conclusions are as follows:

1) The global land average annual and seasonal mean extreme temperature indices all experienced significant long-term changes over the period 1951-2015, with cold threshold indices (frost days, icing days, cold days, and cold nights) decreasing and warm threshold indices (summer days, tropical nights, warm days and warm nights) increasing. The extreme temperature indices based on daily minimum temperature generally had a stronger and more significant trend than those based on daily maximum temperature.

2) The most significant warming in most extreme temperature indices occurred after the mid-1970s, and before the mid-1970s the global land average indices series generally showed no significant change. Most parts of the global land experienced significant warming trends over the period 1951-2015 as a whole, and the largest trends appeared in mid- to high latitudes of the Eurasian continent.

3) The seasonal analysis showed that, during the period of 1951-2015, the global land average annual and seasonal frequency of cold nights and warm days experienced similarly large and significant changes, with the seasonal cold nights decreasing at rates from -0.97 to -1.18 days decade ${ }^{-1}$, and the seasonal warm days increasing at rates from 0.69 to 1.11 days decade ${ }^{-1}$. The most significant seasonal trends of the two extreme indices occurred in the period of 19762015, and the pre-1976 seasonal changes were generally small and statistically insignificant.

4) Most parts of the world experienced warming during the period 1951-2015. However, in the summer and autumn of central and southeastern United States, the indices calculated from the daily maximum temperature did not experience the warming trend, resulting in the so-called warming hole. The warmseason daytime cooling phenomenon also appeared in eastern China to a lesser extent.

5) In most of the $T_{\max }$-based and warm extreme temperature indices series, the signal of volcano eruptions was notable, with the influence of the 1991 Pinatubo eruption on the extreme temperature indices particularly clear for warm days, cold days, and summer days in the boreal summer and autumn in 1992-93.

Acknowledgments. This study is supported by the National Key R\&D Program of China (2018YFA0605603) and the Natural Science Foundation of China (NSFC) (41575003). The authors thank Yang Feng, Kangmin Wen, Xiaoying Xue, Xiaoming Liu, and two anonymous reviewers for their comments and suggestions that greatly improved the manuscript.

\section{REFERENCES}

Aguilar, E., and Coauthors, 2005: Changes in precipitation and temperature extremes in Central America and northern South America, 1961-2003. J. Geophys. Res., 110, D23107, https:// doi.org/10.1029/2005JD006119.

Alexander, L. V., and Coauthors, 2006: Global observed changes in daily climate extremes of temperature and precipitation.J. Geophys. Res., 111, D05109, https://doi.org/10.1029/ 2005JD006290.

Avila, F. B., S. Dong, K. P. Menang, J. Rajczak, M. Renom, M. G. Donat, and L. V. Alexander, 2015: Systematic investigation of gridding-related scaling effects on annual statistics of daily temperature and precipitation maxima: A case study for south-east Australia. Wea. Climate Extremes, 9, 6-16, https:// doi.org/10.1016/j.wace.2015.06.003.

Best, D. J., and D. E. Roberts, 1975: Algorithm AS 89: The upper tail probabilities of Spearman's rho. Appl. Stat., 24, 377, https://doi.org/10.2307/2347111.

Bronaugh, D., 2015: climdex.pcic: PCIC Implementation of Climdex Routines, version 1.1-6. R package, https://CRAN.R-project.org/ package $=$ climdex.pcic.

Brown, P. J., R. S. Bradley, and F. T. Keimig, 2010: Changes in extreme climate indices for the northeastern United States, 1870-2005. J. Climate, 23, 6555-6572, https://doi.org/10.1175/ 2010JCLI3363.1.

Brunet, M., and Coauthors, 2006: The development of a new dataset of Spanish Daily Adjusted Temperature Series (SDATS) (1850-2003). Int. J. Climatol., 26, 1777-1802, https:// doi.org/10.1002/joc.1338.

Caesar, J., L. Alexander, and R. Vose, 2006: Large-scale changes in observed daily maximum and minimum temperatures: Creation and analysis of a new gridded data set. J. Geophys. Res., 111, D05101, https://doi.org/10.1029/2005JD006280.

Cao, L., Y. Zhu, G. Tang, F. Yuan, and Z. Yan, 2016: Climatic warming in China according to a homogenized data set from 2419 stations. Int. J. Climatol., 36, 4384-4392, https://doi.org/ 10.1002/joc. 4639 .

Cerveny, R. S., J. Lawrimore, R. Edwards, and C. Landsea, 2007: Extreme weather records: Compilation, adjudication, and publication. Bull. Amer. Meteor. Soc., 88, 853-860, https://doi.org/ 10.1175/BAMS-88-6-853.

Cleveland, W. S., 1979: Robust locally weighted regression and smoothing scatterplots. J. Amer. Stat. Assoc., 74, 829-836, https://doi.org/10.1080/01621459.1979.10481038.

Cubasch, U., D. Wuebbles, D. Chen, M. C. Facchini, D. Frame, N. Mahowald, and J.-G. Winther, 2013: Introduction. Climate 
Change 2013: The Physical Science Basis, T. F. Stocker et al., Eds., Cambridge University Press, 119-158.

Ding, Y. H., and G. Y. Ren, 2008: Introduction of China Climate Change Science. China Meteorological Press, $281 \mathrm{pp}$.

Donat, M. G., and Coauthors, 2013a: Updated analyses of temperature and precipitation extreme indices since the beginning of the twentieth century: The HadEX2 dataset. J. Geophys. Res. Atmos., 118, 2098-2118, https://doi.org/10.1002/jgrd.50150.

_ , L. V. Alexander, H. Yang, I. Durre, R. Vose, and J. Caesar, 2013b: Global land-based datasets for monitoring climatic extremes. Bull. Amer. Meteor. Soc., 94, 997-1006, https://doi.org/ 10.1175/BAMS-D-12-00109.1.

Dunn, R. J. H., M. G. Donat, and L. V. Alexander, 2014: Investigating uncertainties in global gridded datasets of climate extremes. Climate Past, 10, 2171-2199, https://doi.org/10.5194/ cp-10-2171-2014.

Easterling, D. R., 2000: Climate extremes: Observations, modeling, and impacts. Science, 289, 2068-2074, https://doi.org/10.1126/ science.289.5487.2068.

— L. L. V. Alexander, A. Mokssit, and V. Detemmerman, 2003: CCI/CLIVAR Workshop to Develop Priority Climate Indices. Bull. Amer. Meteor. Soc., 84, 1403-1407, https://doi.org/ 10.1175/BAMS-84-10-1409.

Folland, C. K., T. R. Karl, and J. R. Christy, 2001: Observed climate variability and change. Climate Change 2001: The Scientific Basis, J. H. Houghton et al., Eds., Cambridge University Press, 99-181.

Fonseca, D., M. J. Carvalho, M. Marta-Almeida, P. Melo-Gonçalves, and A. Rocha, 2016: Recent trends of extreme temperature indices for the Iberian Peninsula. Phys. Chem. Earth Parts ABC, 94, 66-76, https://doi.org/10.1016/j.pce.2015.12.005.

Frei, C., and C. Schär, 2001: Detection probability of trends in rare events: theory and application to heavy precipitation in the Alpine region. J. Climate, 14, 1568-1584, https://doi.org/ 10.1175/1520-0442(2001)014<1568:DPOTIR > 2.0.CO;2.

Frich, P., L. Alexander, P. Della-Marta, B. Gleason, M. Haylock, A. Klein Tank, and T. Peterson, 2002: Observed coherent changes in climatic extremes during the second half of the twentieth century. Climate Res., 19, 193-212, https://doi.org/ 10.3354/cr019193.

Handmer, J. Y., and Coauthors, 2012: Changes in impacts of climate extremes: Human systems and ecosystems. Managing the Risks of Extreme Events and Disasters to Advance Climate Change Adaptation, C. B. Field et al., Eds., Cambridge University Press, 231-290, https://www.ipcc.ch/site/assets/uploads/ 2018/03/SREX-Chap4_FINAL-1.pdf.

Hansen, J., M. Sato, R. Ruedy, K. Lo, D. W. Lea, and M. MedinaElizade, 2006: Global temperature change. Proc. Natl. Acad. Sci. USA, 103, 14 288-14 293, https://doi.org/10.1073/pnas.0606291103.

Hartmann, D. L., and Coauthors, 2013: Observations: Atmosphere and surface. Climate Change 2013: The Physical Science Basis, T. F. Stocker et al., Eds., Cambridge University Press, 159218.

Hollander, M., and D. A. Wofle, 1973: Nonparametric Statistical Methods. John Wiley \& Sons, 185-194 pp.

Jayawardena, I. M. S. P., D. W. T. T. Darshika, and H. M. R. C. Herath, 2018: Recent trends in climate extreme indices over Sri Lanka. Amer. J. Climate Change, 07, 586-599, https:// doi.org/10.4236/ajcc.2018.74036.

Jones, P. D., and M. Hulme, 1996: Calculating regional climatic time series for temperature and precipitation: Methods and illustrations. Int. J. Climatol., 16, 361-377, https://doi.org/10.1002/(SICI) 1097-0088(199604)16:4<361::AID-JOC53>3.0.CO;2-F.
_ D. H. Lister, and Q. Li, 2008: Urbanization effects in large-scale temperature records, with an emphasis on China. J. Geophys. Res., 113, D16122, https://doi.org/10.1029/2008JD009916.

- — , T. J. Osborn, C. Harpham, M. Salmon, and C. P. Morice, 2012: Hemispheric and large-scale land-surface air temperature variations: An extensive revision and an update to 2010. J. Geophys. Res., 117, D05127, https://doi.org/10.1029/ $2011 \mathrm{jd} 017139$.

Kendall, M. G., 1955: Rank Correlation Methods. Charles Griffin, $196 \mathrm{pp}$.

Klein Tank, A. M. G., and G. P. Können, 2003: Trends in indices of daily temperature and precipitation extremes in Europe, 1946-99. J. Climate, 16, 3665-3680, https://doi.org/10.1175/ 1520-0442(2003)016<3665:TIIODT $>2.0$.CO;2.

, and Coauthors, 2002: Daily dataset of 20th-century surface air temperature and precipitation series for the European Climate Assessment: European temperature and precipitation series. Int. J. Climatol., 22, 1441-1453, https://doi.org/10.1002/ joc.773.

— , and Coauthors, 2006: Changes in daily temperature and precipitation extremes in central and south Asia. J. Geophys. Res., 111, D16105, https://doi.org/10.1029/2005JD006316.

Kunkel, K. E., X.-Z. Liang, J. Zhu, and Y. Lin, 2006: Can CGCMs simulate the twentieth-century "warming hole" in the central United States? J. Climate, 19, 4137-4153, https://doi.org/ 10.1175/JCLI3848.1.

Lacis, A., J. Hansen, and M. Sato, 1992: Climate forcing by stratospheric aerosols. Geophys. Res. Lett., 19, 1607-1610, https://doi.org/10.1029/92GL01620.

Lawrimore, J. H., M. J. Menne, B. E. Gleason, C. N. Williams, D. B. Wuertz, R. S. Vose, and J. Rennie, 2011: An overview of the Global Historical Climatology Network monthly mean temperature data set, version 3. J. Geophys. Res., 116, D19121, https://doi.org/10.1029/2011JD016187.

Leibensperger, E. M., and Coauthors, 2012: Climatic effects of 1950-2050 changes in US anthropogenic aerosols-Part 2: Climate response. Atmos. Chem. Phys., 12, 3349-3362, https:// doi.org/10.5194/acp-12-3349-2012.

Li, Q., and J. Huang, 2013: Effects of urbanization on extreme warmest night temperatures during summer near Bohai. Acta Meteor. Sin., 27, 808-818, https://doi.org/10.1007/ s13351-013-0602-0.

Li, Z., and Z. Yan, 2009: Homogenized daily mean/maximum/ minimum temperature series for China from 1960-2008. Atmos. Ocean. Sci. Lett., 2, 237-243, https://doi.org/10.1080/ 16742834.2009.11446802.

_ , F. Niu, J. Fan, Y. Liu, D. Rosenfeld, and Y. Ding, 2011: Longterm impacts of aerosols on the vertical development of clouds and precipitation. Nat. Geosci., 4, 888-894, https://doi.org/ 10.1038/ngeo1313.

Mann, H. B., 1945: Nonparametric tests against trend. Econ. Soc., 13, 245-259, https://doi.org/10.2307/1907187.

Menne, M. J., and C. N. Williams, 2009: Homogenization of temperature series via pairwise comparisons. J. Climate, 22, 17001717, https://doi.org/10.1175/2008JCLI2263.1.

— Daily (GHCN-Daily), version 3.12. NOAA National Climatic Data Center, accessed 13 August 2014, https://doi.org/ 10.7289/V5D21VHZ.

, I. Durre, R. S. Vose, B. E. Gleason, and T. G. Houston, 2012b: An overview of the Global Historical Climatology Network-Daily database. J. Atmos. Oceanic Technol., 29, 897-910, https://doi.org/10.1175/JTECH-D-11-00103.1. 
New, M., and Coauthors, 2006: Evidence of trends in daily climate extremes over southern and west Africa.J. Geophys. Res., 111, D14102, https://doi.org/10.1029/2005JD006289.

Pan, Z. T., R. W. Arritt, E. S. Takle, W. J. Gutowski, C. J. Anderson, and M. Segal, 2004: Altered hydrologic feedback in a warming climate introduces a "warming hole." Geophys. Res. Lett., 31, L17109, https://doi.org/10.1029/2004GL020528.

Peterson, T. C., 2003: Assessment of urban versus rural in situ surface temperatures in the contiguous United States: No difference found. J. Climate, 16, 2941-2959, https://doi.org/ 10.1175/1520-0442(2003)016<2941:AOUVRI > 2.0.CO;2.

—, 2005: Climate change indices. WMO Bull., 54, 83-86.

— , and M. J. Manton, 2008: Monitoring changes in climate extremes-A tale of international collaboration. Bull. Amer. Meteor. Soc., 89, 1266-1271, https://doi.org/10.1175/2008BAMS2501.1.

__ , and Coauthors, 1998: Homogeneity adjustments of in situ atmospheric climate data: A review. Int. J. Climatol., 18, 1493-1517, https://doi.org/10.1002/(SICI)1097-0088(19981115) 18:13<1493::AID-JOC329>3.0.CO;2-T.

- and Coauthors, 2002: Recent changes in climate extremes in the Caribbean region. J. Geophys. Res., 107, 4601, https:// doi.org/10.1029/2002JD002251.

_-, X. Zhang, M. Brunet-India, and J. L. Vázquez-Aguirre, 2008: Changes in North American extremes derived from daily weather data. J. Geophys. Res., 113, https://doi.org/10.1029/ 2007JD009453.

Qian, Y., L. Ruby Leung, S. J. Ghan, and F. Giorgi, 2003: Regional climate effects of aerosols over China: Modeling and observation. Tellus, 55B, 914-934, https://doi.org/10.1046/j.14356935.2003.00070.x.

Ren, G., 2015: Urbanization as a major driver of urban climate change. Adv. Climate Change Res., 6, 1-6, https://doi.org/ 10.1016/j.accre.2015.08.003.

— temperature indices of national stations over Mainland China, 1961-2008. J. Climate, 27, 2340-2360, https://doi.org/10.1175/ JCLI-D-13-00393.1.

, — Z Z. Chu, J. Zhou, A. Zhang, J. Guo, and X. Liu, 2008: Urbanization effects on observed surface air temperature trends in north China. J. Climate, 21, 1333-1348, https:// doi.org/10.1175/2007JCLI1348.1.

_- Y. Ren, Q. Li, and W. Xu, 2014: An overview on global land surface air temperature change. Diqiu Kexue Jinzhan, 29, 934946, https://doi.org/doi:10.11867/j.issn.1001-8166.2014.08.0934.

Royston, P., 1982: Algorithm AS 181: The W test for normality. Appl. Stat., 31, 176-180, https://doi.org/10.2307/2347986.

Sato, M., J. E. Hansen, M. P. McCormick, and J. B. Pollack, 1993: Stratospheric aerosol optical depths, 1850-1990. J. Geophys. Res., 98, 22 987-22 994, https://doi.org/10.1029/93JD02553.

Sen, P. K., 1968: Estimates of the regression coefficient based on Kendall's tau. J. Amer. Stat. Assoc., 63, 1379-1389, https:// doi.org/10.1080/01621459.1968.10480934.

Seneviratne, S. I., and Coauthors, 2012: Changes in impacts of climate extremes and their impacts on the natural physical environment. Managing the Risks of Extreme Events and Disasters to Advance Climate Change Adaptation, C. B. Field et al., Eds., Cambridge University Press, 109230.

Sharma, D., and M. S. Babel, 2014: Trends in extreme rainfall and temperature indices in the western Thailand. Int. J. Climatol., 34, 2393-2407, https://doi.org/10.1002/joc.3846.

Sillmann, J., V. V. Kharin, X. Zhang, F. W. Zwiers, and D. Bronaugh, 2013: Climate extremes indices in the CMIP5 multimodel ensemble: Part 1. Model evaluation in the present climate. J. Geophys. Res., 118, 1716-1733, https://doi.org/ 10.1002/jgrd.50203.

Sun, X., G. Ren, A. B. Shrestha, Y.-Y. Ren, Q.-L. You, Y.-J. Zhan, Y. Xu, and R. Rajbhandari, 2017a: Changes in extreme temperature events over the Hindu Kush Himalaya during 19612015. Adv. Climate Change Res., 8, 157-165, https://doi.org/ 10.1016/j.accre.2017.07.001.

$\longrightarrow, \ldots$, W. Xu, Q. Li, and Y. Ren, 2017b: Global land-surface air temperature change based on the new CMA GLSAT data set. Sci. Bull., 62, 236-238, https://doi.org/10.1016/j.scib.2017.01.017.

Sun, Y., X. Zhang, G. Ren, F. W. Zwiers, and T. Hu, 2016: Contribution of urbanization to warming in China. Nat. Climate Change, 6, 706-709, https://doi.org/10.1038/NCLIMATE2956.

Trewin, B. C., 2001: Extreme temperature events in Australia. Ph.D. thesis, University of Melbourne, $417 \mathrm{pp}$.

_ 2013: A daily homogenized temperature data set for Australia. Int. J. Climatol., 33, 1510-1529, https://doi.org/10.1002/ joc. 3530.

_ and A. C. F. Trevitt, 1996: The development of composite temperature records. Int. J. Climatol., 16, 1227-1242, https:// doi.org/10.1002/(SICI)1097-0088(199611)16:11<1227::AIDJOC82>3.0.CO;2-P.

Vincent, L. A., and É. Mekis, 2006: Changes in daily and extreme temperature and precipitation indices for Canada over the twentieth century. Atmos.-Ocean, 44, 177-193, https://doi.org/ 10.3137/ao.440205.

—, X. Zhang, B. R. Bonsal, and W. D. Hogg, 2002: Homogenization of daily temperatures over Canada. J. Climate, 15, 1322-1334, https://doi.org/10.1175/1520-0442(2002)015<1322: HODTOC $>2.0 . \mathrm{CO} ; 2$.

— perature extremes in South America 1960-2000. J. Climate, 18, 5011-5023, https://doi.org/10.1175/JCLI3589.1.

_- and Coauthors, 2011: Observed trends in indices of daily and extreme temperature and precipitation for the countries of the western Indian Ocean, 1961-2008. J. Geophys. Res., 116, D10108, https://doi.org/10.1029/2010JD015303.

_ , X. L. Wang, E. J. Milewska, H. Wan, F. Yang, and V. Swail, 2012: A second generation of homogenized Canadian monthly surface air temperature for climate trend analysis. J. Geophys. Res., 117, D18110, https://doi.org/10.1029/2012JD017859.

Von Storch, H., and A. Navarra, Eds., 1999: Misuses of statistical analysis in climate research. Analysis of Climate VariabilityApplications of Statistical Techniques. Springer-Verlag, 11-26.

Wang, X. L., 2008a: Penalized maximal F test for detecting undocumented mean shift without trend change. J. Atmos. Oceanic Technol., 25, 368-384, https://doi.org/10.1175/ 2007JTECHA982.1.

- 2008b: Accounting for autocorrelation in detecting mean shifts in climate data series using the penalized maximal $\mathrm{t}$ or $\mathrm{F}$ test. J. Appl. Meteor. Climatol., 47, 2423-2444, https://doi.org/ 10.1175/2008JAMC1741.1.

- , and V. R. Swail, 2001: Changes of extreme wave heights in Northern Hemisphere oceans and related atmospheric circulation regimes. J. Climate, 14, 2204-2221, https://doi.org/ 10.1175/1520-0442(2001)014<2204:COEWHI >2.0.CO;2.

_ , and Y. Feng, 2010: RHtests V3 User Manual. Climate Research Division, Atmospheric Science and Technology Directorate. Science and Technology Branch, Environment Canada, 27 pp., http:// etccdi.pacificclimate.org/RHtest/RHtestsV3_UserManual.doc. - and _ 2013: RHtests V4 User Manual. Climate Research Division, Atmospheric Science and Technology Directorate. 
Science and Technology Branch, Environment Canada, 29 pp., http://etccdi.pacificclimate.org/RHtest/RHtestsV4_UserManual_ 20July2013.pdf.

Wijngaard, J. B., A. Tank, and G. P. Konnen, 2003: Homogeneity of 20th century European daily temperature and precipitation series. Int. J. Climatol., 23, 679-692, https://doi.org/10.1002/ joc. 906 .

WMO, 2008: Guide to Meteorological Instruments and Methods of Observation. 7th ed. WMO 8, 33 pp.

Xu, W., Q. Li, X. L. Wang, S. Yang, L. Cao, and Y. Feng, 2013: Homogenization of Chinese daily surface air temperatures and analysis of trends in the extreme temperature indices. J. Geophys. Res. Atmos., 118, 9708-9720, https://doi.org/ 10.1002/jgrd.50791.

_ , and Coauthors, 2018: A new integrated and homogenized global monthly land surface air temperature dataset for the period since 1900. Climate Dyn., 50, 2513-2536, https://doi.org/ 10.1007/s00382-017-3755-1.

$\mathrm{Xu}, \mathrm{Y}$., W. Xu, and Q. Li, 2014: Report on the development and evaluation of global land daily temperature and precipitation data sets. National Meteorological Information Center of China Meteorological Administration, $21 \mathrm{pp}$.

Yan, Z., and Coauthors, 2002: Trends of extreme temperatures in Europe and China based on daily observations. Climatic Change, 53, 355-392, https://doi.org/10.1023/A:1014939413284.

Zhai, P., and X. Pan, 2003: Trends in temperature extremes during 1951-1999 in China. Geophys. Res. Lett., 30, 1913, https:// doi.org/10.1029/2003GL018004.

Zhang, L., G. Ren, J. Liu, Y. Zhou, Y. Ren, A. Zhang, and Y. Feng, 2011: Urban effect on trends of extreme temperature indices at Beijing Meteorological Station. Chin. J. Geophys., 54, 1150-1159.

Zhang, X., and Y. Feng, 2004: RClimDex User Manual. Climate Research Branch, Environment Canada, 23 pp.
- L. A. Vincent, W. D. Hogg, and A. Niitsoo, 2000: Temperature and precipitation trends in Canada during the 20th century. Atmos.-Ocean, 38, 395-429, https://doi.org/10.1080/ 07055900.2000 .9649654 .

, G. Hegerl, F. W. Zwiers, and J. Kenyon, 2005b: Avoiding inhomogeneity in percentile-based indices of temperature extremes. J. Climate, 18, 1641-1651, https://doi.org/10.1175/ JCLI3366.1.

— treme indices from 1950 to 2003. J. Geophys. Res., 110, D22104, https://doi.org/10.1029/2005JD006181.

—, F. W. Zwiers, G. C. Hegerl, F. H. Lambert, N. P. Gillett, S. Solomon, P. A. Stott, and T. Nozawa, 2007: Detection of human influence on twentieth-century precipitation trends. Nature, 448, 461-465, https://doi.org/10.1038/nature06025.

,-- , and G. Hegerl, 2009: The influences of data precision on the calculation of temperature percentile indices. Int. J. Climatol., 29, 321-327, https://doi.org/10.1002/joc.1738.

—, L. Alexander, G. C. Hegerl, P. Jones, A. K. Tank, T. C. Peterson, B. Trewin, and F. W. Zwiers, 2011: Indices for monitoring changes in extremes based on daily temperature and precipitation data. Wiley Interdiscip. Rev.: Climate Change, 2 , 851-870, https://doi.org/10.1002/wcc.147.

Zhou, L., R. E. Dickinson, Y. Tian, J. Fang, Q. Li, R. K. Kaufmann, C. J. Tucker, and R. B. Myneni, 2004: Evidence for a significant urbanization effect on climate in China. Proc. Natl. Acad. Sci. USA, 101, 9540-9544, https://doi.org/ 10.1073/pnas.0400357101.

Zhou, Y., and G. Ren, 2009: The Effect of urbanization on maximum, minimum temperatures and daily temperature range in North China. Plateau Meteor., 28, 1158-1994.

- , and 2011: Change in extreme temperature event frequency over mainland China, 1961-2008. Climate Res., 50, 125-139, https://doi.org/10.3354/cr01053. 